\title{
Improvisational Lines The Architecture of an Informal Syrian Refugee Settlement
}

by

Sammy Yehia

A thesis submitted to the Faculty of Graduate and Postdoctoral Affairs in partial fulfillment of the requirements for the degree of

Master of Architecture

Carleton University

Ottawa, Ontario

(C) 2015

Sammy Yehia 


\begin{abstract}
The thesis project responds to Syrian refugee camps in Lebanon; in particular the illegal settlements that have been rapidly multiplying due to massive migration of the displaced population. The research will first examine the cultural and social effects of life in exile in order to understand the current reality of the refugee community. The definition of the cultural context will lay a basis for an appropriate architectural response. The uncertainty of the refugee condition does not allow for specific siting, but offers instead a larger geographical context defined by its climate, topography, resources and socio-political conditions.
\end{abstract}

The project will be articulated around the notions of temporality and improvised methodologies. The conception process will take into consideration the unpredictability of circumstances, as well as the eventuality of the refugees going back home. The process will also favor a do-it-yourself method as a response to the frequent motion of the refugee population. The research will try to answer the following questions: What are the architectural values of a clandestine settlement? What are the factors that define it? How can a temporal structure instill stability and provide a sense of belonging? And finally, what are the specific needs of a mainly underage refugee population?

The conception will evolve through an iterative design method. The final project will be presented as a series of prototypes, each relating to a specific aspect of the problem. An exploration on both the urban and the architectural scale will be necessary. The first will provide a secure environment and an adequate infrastructure, while the second will provide a solid and sanitary shelter prototype. The whole strategy will be based a number of conditions, such as rapid construction, low cost of production, simplicity of construction methods, use of local materials and quality of the built environment, amongst others. 
Table of contents

Abstract ..................................................... ii

Introduction ................................................ 2

1 Emergency Design Principles

Temporaryhousingtypology............................. 4

2 Context Analysis

5

Topography

Key concerns for temporary housing.

6

7

Climatic conditions and resource

availability

Social responsibility of the 9

design professional

11

The socio-political structure

From camp to settlement 13

15

Built environment analysis

Frederick Cuny's cluster model

17

\section{Design Project}

Cultural reference

21

The cluster model and urban planning

23

Basic prototype and modular adaptation ........ 27

Constructive detailing /physical ....................... 34

model exploration

Postscript

Bibliography. 46

List of Figures 48

Appendix A: Al Zaatari Camp, Jordan 50 


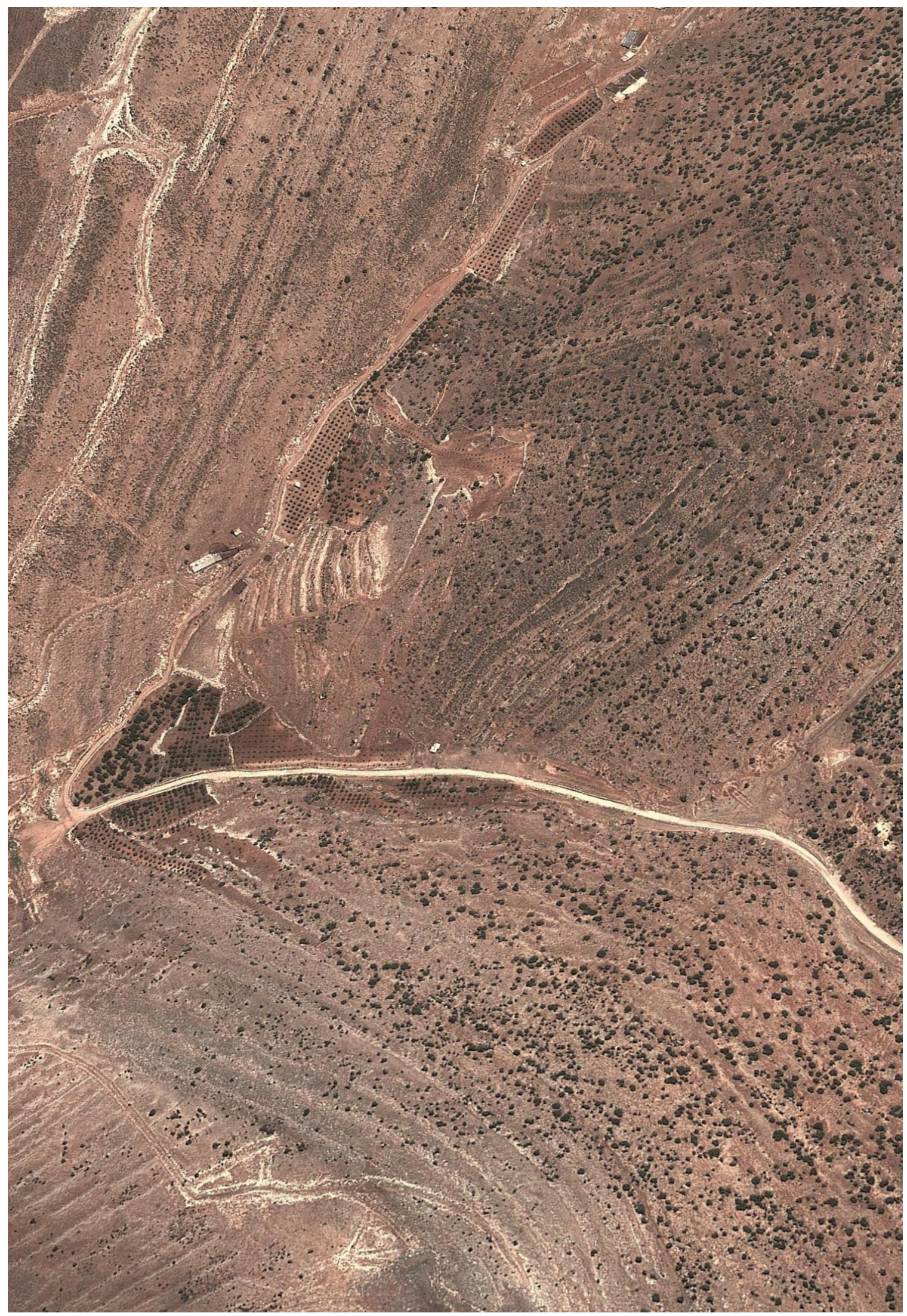

Figure 1. Satellite view of the Bekaa Region. Google Earth, March 2015 


\section{Introduction}

The Syrian civil war is an ongoing armed conflict between the government of President Bashar Al-Assad and the different rebel factions seeking his removal. Now in its fourth year, the war has generated a humanitarian crisis of disastrous proportions, displacing over six million people internally and forcing more than three million to flee their country to immediate neighbors including Turkey, Lebanon, Jordan and Iraq, placing unprecedented strains on communities, infrastructure and services in host countries.

According to the United Nations High Commissioner for Refugees (UNHCR), there has been a massive escalation of arrivals in 2014. This has resulted in the creation of ad-hoc refugee camps to accommodate the displaced victims. Women and children make up three-quarters of the refugee population and the vast majority of them are dependent on aid, arriving with little more than the clothes on their backs. While some camps, organized by the UNHCR and local governments, provide relatively good living conditions, the majority of others are improvised by the refugees themselves and offer an unhealthy living environment. As they grow larger and older, the camps become breeding grounds for violent crime and disease, with reports of violence against women increasing exponentially. In Lebanon, where more than eight hundred thousand refugees have been counted, the absence of organized settlements forces the displaced population to live in informal settlements or abandoned squats, increasing their economic vulnerability and social exclusion.

With an average lifespan of seven to seventeen years, the refugee camps need to be carefully planned microcities, taking into consideration the safety and wellness of their inhabitants. The goal of this thesis is to shed light on the main architectural necessities of the typical Syrian refugee camp, while exploring potential solutions through the study of previous humanitarian interventions. 


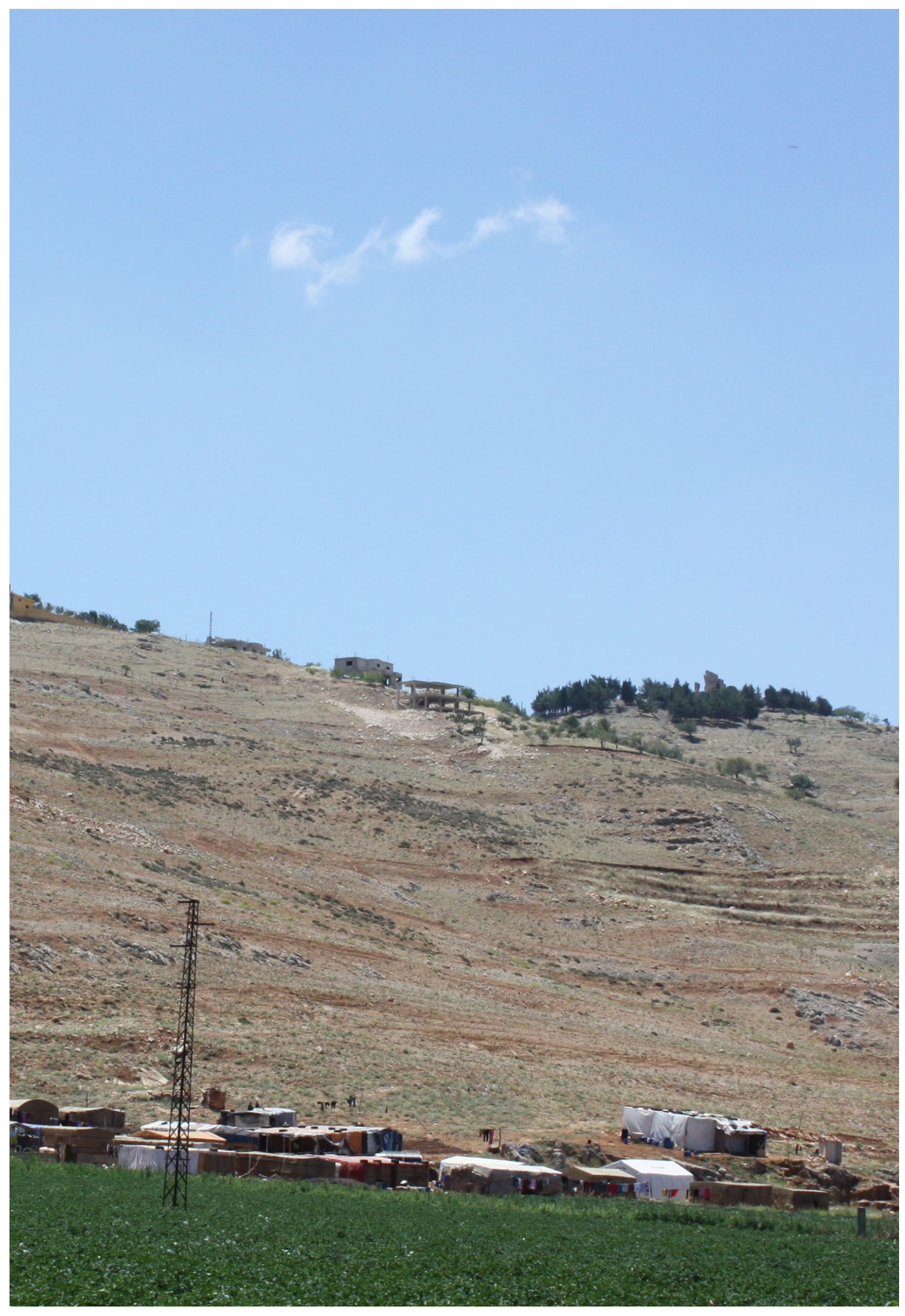

Figure 2. Informal refugee settlement near Anjar, Lebanon. Photo by author. June 2014. 


\section{Temporary housing typology}

The primary purpose of a refugee camp is to provide shelter for people displaced by war or political oppression. Therefore, the first step is to look into the different types of emergency shelter in the context of disaster. Shelters come in various forms, largely influenced by the severity of the crisis and the amount of humanitarian aid available ${ }^{1}$.

The first type is "Emergency Sheltering", usually used at the height of a crisis. It is intended to last from several days to several weeks with the main function of providing physical protection to refugees. It takes the form of lightweight tents or self-built structures. The second type is "Temporary Sheltering" which is employed after the height of an emergency, and typically lasts anywhere from several weeks to several months. It provides shelter and allows for the provision of food and medical assistance. These may take the form of adapted shipping containers, caravans or prefabricated housing structures. The third and last type is "Temporary Housing" designed to last longer, from several months to several years. These enable people to live in dignity and provide adequate levels of services. They can take many forms but usually consist of specialized housing units donated by NGOs and governments.

In times of crisis, the priority is to offer an adequate shelter meeting basic human needs to all the displaced victims. As time goes by, the typology of the average shelter should shift from the minimal standard requirement to the fully functional housing unit, allowing a healthy and fulfilling lifestyle.

1 LIZARRALDE, Gonzalo. Rebuilding After Disasters: From Emergency to Sustainability. London: Spon Press, 2010, p.70 


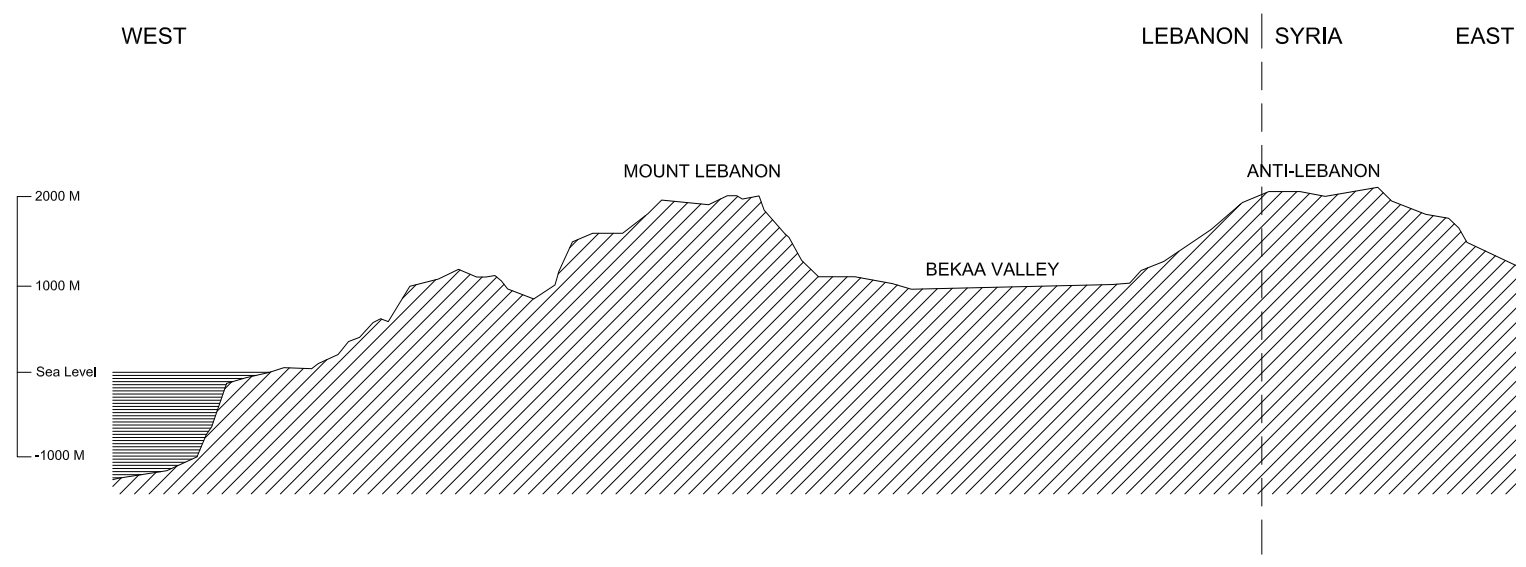

Figure 3. Cross section of Lebanese topography in East-West axis.

\section{Topography}

The geographical characteristics of the region are crucial to understand the flux of populations in the context of the civil war. The drawing (Fig.3) represents a cross section of the Lebanese-Syrian topography in an East-West axis, composed of two mountain chains with a narrow plateau in between called the Bekaa Valley. The project will be located in the central region of the valley, as a large portion of the displaced population has settled in this rural area due to its proximity to the Syrian border, as well as the possibility of finding work in the neighboring agricultural fields. Although the Lebanese-Syrian frontier is reinforced by a geological obstacle (the mountain chain), the separation between the two nations seems to have completely disappeared in people minds, as the refugees have been crossing freely since the beginning of the war. 


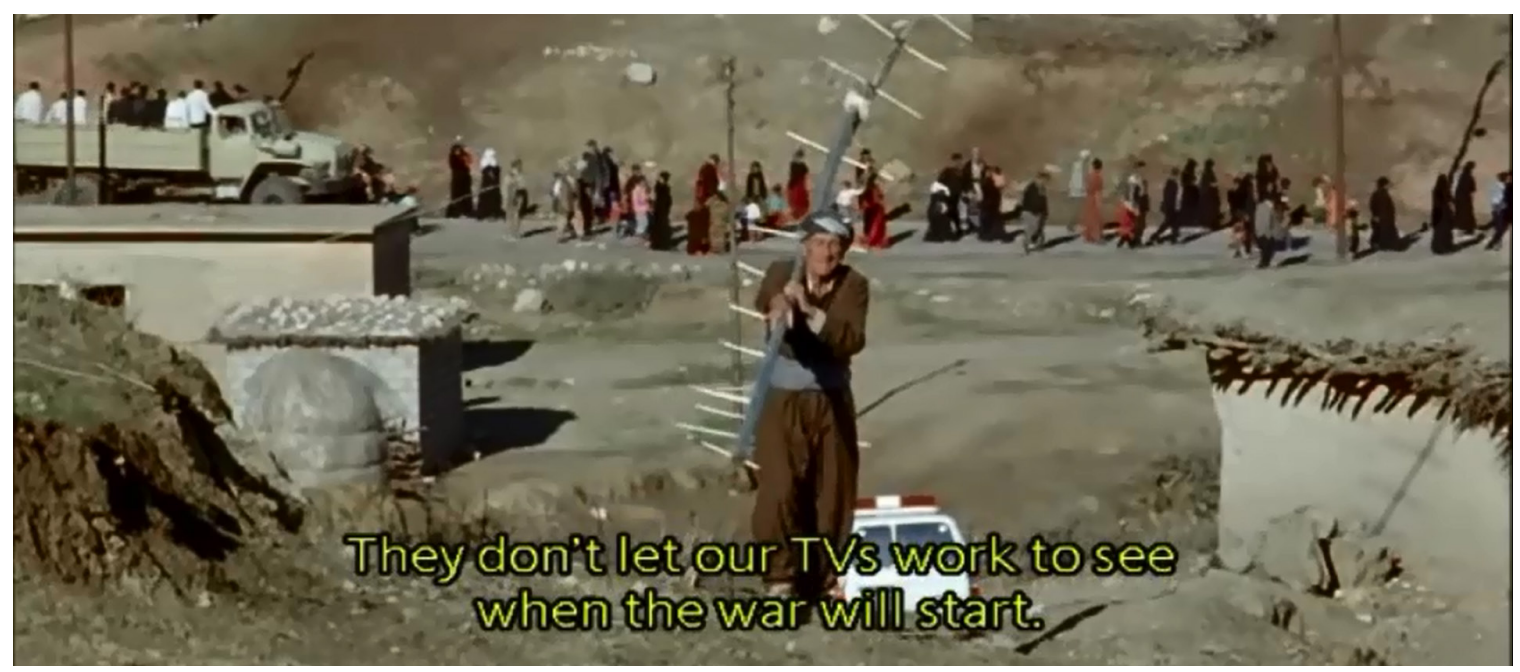

Figure 4. Still from the movie Turtles Can Fly. Bahman Ghobadi (dir.), IFC Films, 2004.

Key concerns for temporary housing

The design process of a temporary housing project is guided by a number of principles and key concerns, aiming to increase the efficiency of the response ${ }^{2}$. By acknowledging these concerns, the organizer is able to avoid complications that could cost both money and human lives. The first element is the speed of delivery. The shelters must be available as quickly as possible after the disaster as families need a secure and private place to regain their autonomy and begin recovery. The second principle seeks a balance between providing and empowering. Temporary housing projects often fall at two ends of the spectrum: either they are top-down with a solution completely provided by the government or NGO, or they are total- ly bottom-up, relying only on self-help. A hybrid solution can benefit from both structures and generate a more efficient result. The third and fourth elements are cost and unit design. Those two are interdependent; as the cost of construction, maintenance and de-installation are very much related to the unit design and choice of materials. Finally, a last item is the location and its accessibility to services. Temporary housing should be located in the city whenever possible. It allows residents to draw on existing services such as schools, clinics and bus lines. On the other hand it may be quicker to build large settlements outside the city, because land is more readily available and more houses can be erected at once. These however would require additional links to services and infrastructure. 


\section{Climatic conditions and resource availability}

The Bekaa valley stretches over $120 \mathrm{~km}$ in length and about $16 \mathrm{~km}$ in width, and is located about $30 \mathrm{~km}$ east of Beirut. The plateau has an altitude of about $1000 \mathrm{~m}$ above sea level, which can cause extreme climatic conditions.

The Central Bekaa region is semi-arid with 500-600 mm precipitation a year, and temperatures averaging $35^{\circ} \mathrm{C}$ in the summer and $8^{\circ} \mathrm{C}$ in the winter, although below freezing temperatures have been recorded in the past few years $^{3}$. The Bekaa Valley is the main agricultural region in the country representing more than $40 \%$ of the cultivated land. Its main agricultural products are cereal (mainly wheat and barley), grapes (for wine production), vegetables, potatoes, tobacco, as well as the raising of poultry, sheep and goats. The vast majority of the valley's land use is dedicated to industrial crops, with cattle rearing concentrated on the eastern slopes of the valley, where soil fertility is low. Lebanon is relatively rich in water

3 ERNER, Dorte, David R. LEE, Maximillian ASHWILL and Robert WILBY. Increasing Resilience to Climate Change in the Agricultural Sector of the Middle East. Washington DC: The World Bank, 2013, p.52 resources (both rivers and groundwater tables) supplying the valley with most of its water needs for irrigation. However, the water supplies are declining and becoming scarce due to the overconsumption of the resources and the pollution through toxic pesticide use.

The Bekaa Valley is also one of Lebanon's poorest regions with up to $25 \%$ of its population living under the national poverty line. The factors causing this income inequity are the high rates of unemployment, the lack of education and the low literacy rates among the poor. The urban areas are also affected by recurring factors such as small landholdings and underperforming cereal and livestock sectors relative to other high value crops. According to 1998 Agriculture Census, two-thirds of Lebanon's farmers were estimated to be only partially employed in agriculture, with most having second jobs ${ }^{4}$.

4 lbid., p.56 

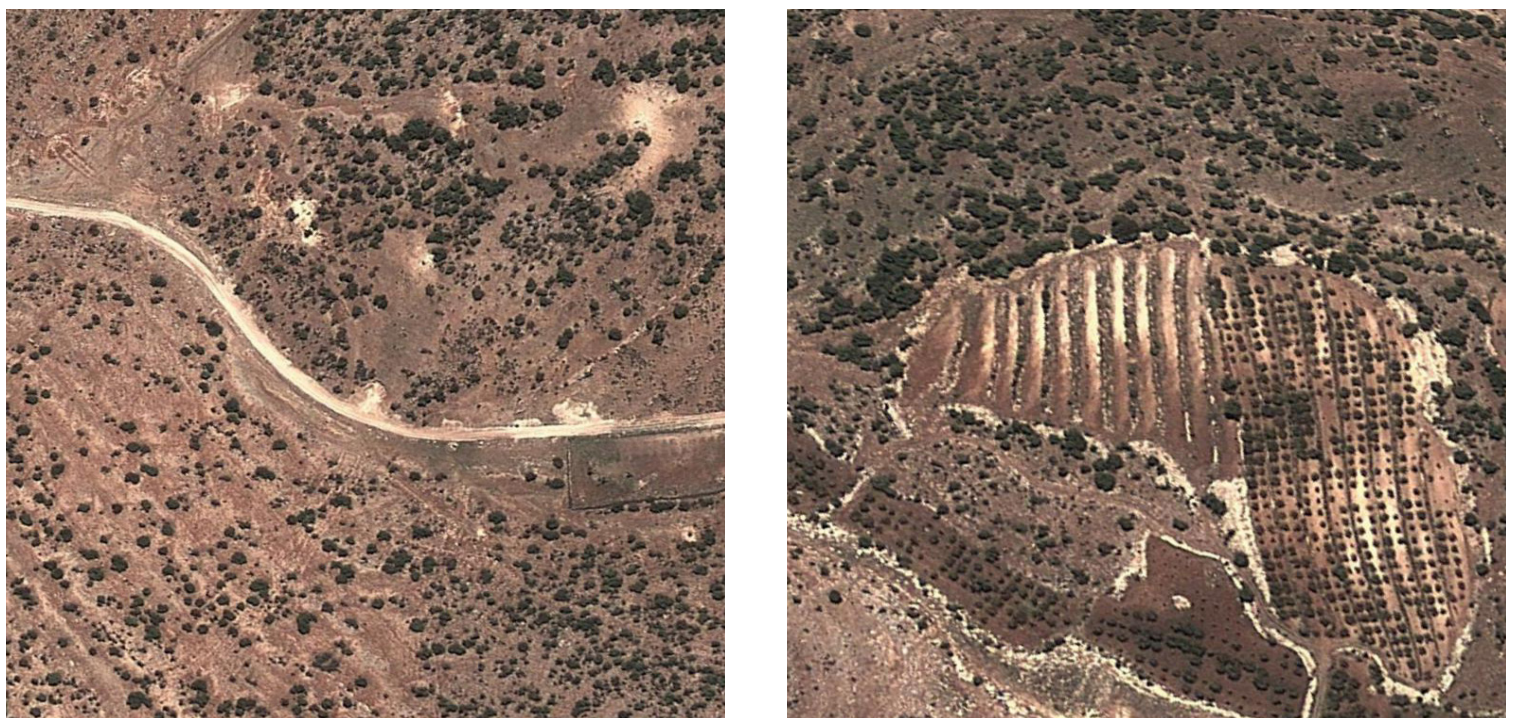

Figure 5. Satellite view of the Bekaa Valley Region showing existing road and agricultural lands. Google Earth, March 2015. 


\section{Social responsibility of the design profes-}

sional

While the development principles evoked earlier focus on matters of economic and practical concerns, the social sustainability of the intervention should not be neglected. The often precarious social condition in the refugee camps should be strengthened by an inclusive conceptual approach, as a way to accomplish social cohesion.

In the book Rebuilding After Disasters: From Emergency to Sustainability (Lizarralde, 2010), the authors have selected the following objectives to be considered during the process ${ }^{5}$ :
1. The development of autonomy for social groups and individuals. This comes through the construction of suitable infrastructure that would help reduce the dependency of the marginalized and vulnerable groups.

2. The promotion of social integration, in opposition to social segregation on age, race and religion. It includes citizens' participation in decision-making and political responsibility.

3. The preservation of values and cultural heritage, through the consideration of collective memory and traditional construction knowhow. This process will combine local architectural values and global tendencies in design and urban planning.

5 LIZARRALDE, Gonzalo. Rebuilding After Disasters: From Emergency to Sustainability. London: Spon Press, 2010, p.206 


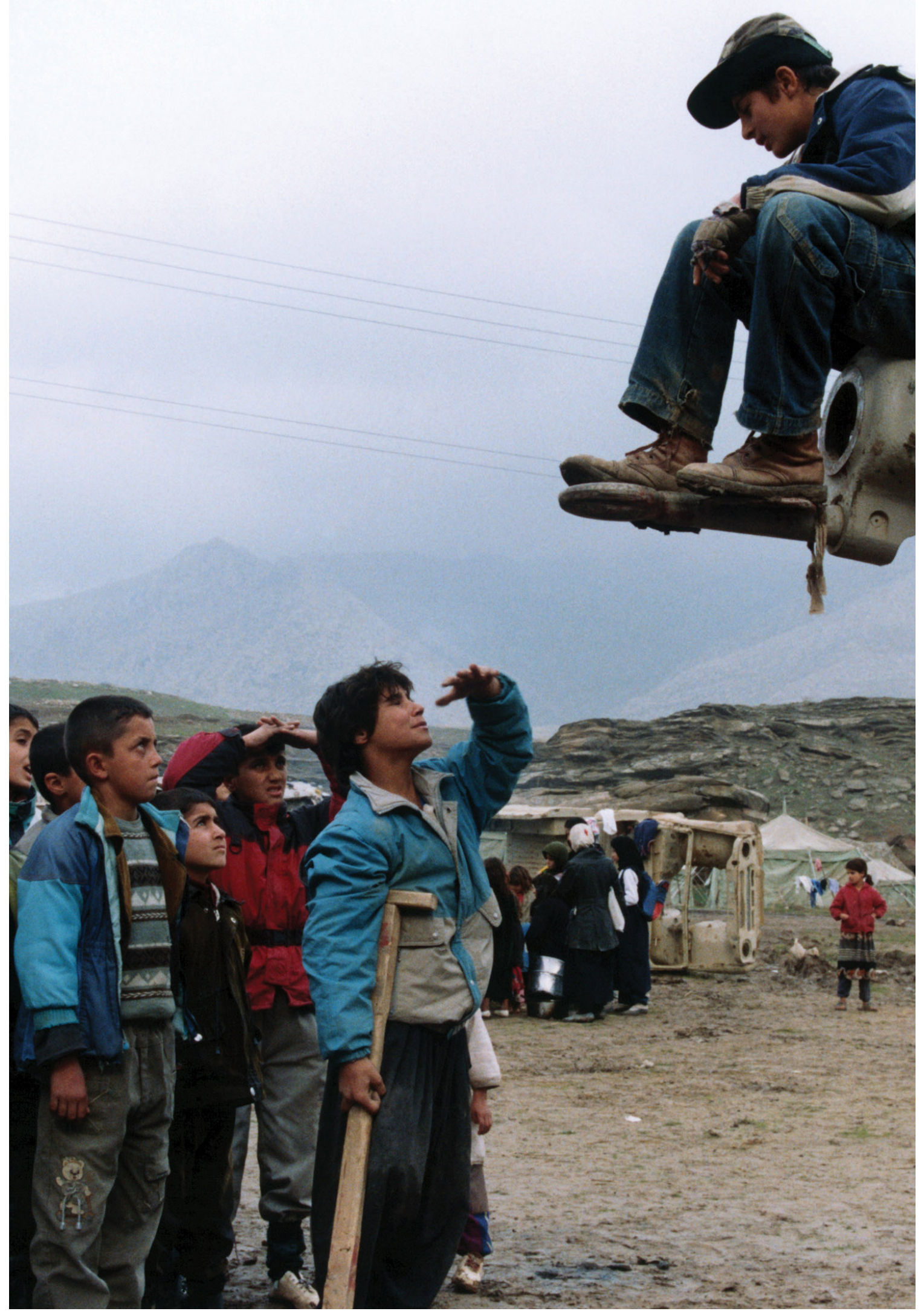

Figure 6. Kurdish refugee children, from the movie Turtles Can Fly. Bahman Ghobadi (dir.), IFC Films, 2004. 


\section{The socio-political structure}

Most of the documentation used in this research, relating to the existing settlements, was gathered during a two day visit of three refugee camps close to the village of Anjar, in the Bekaa region. Guided by an NGO employee, we were able to go inside the camps and the tents in order to document their condition, as well as interview the refugees. The settlements were relatively small, containing between 15 and 30 tents each.

According to the guide, all the NGOs and humanitarian organizations have to work under the supervision of the UN and UNHCR. The geographic location of their intervention is assigned to them by the UN as a way to insure help to all the refugees around the country. Some NGOs offer specialized aid, like Handicap International who works with wounded and handicapped people. Although the refugees have to register their names with the UN in order to have access to humanitarian aid, some of them choose not to for fear of being persecuted in the future. The registered refugees are provided with the following aid and equip- ment: kitchen kits, medical kits, equipment for the handicapped (including wheelchairs), food stamps, ATM cards with money for fuel heaters, water, water tanks, dry toilets, activities for children, schooling, and other essentials. In order to afford the land rent and the material for tent construction, the refugees usually work in the neighboring agricultural fields.

Although the documented settlements are illegal, the refugees still have to pay a fee (70 CAD /month/tent) to the landowner in exchange for permission to build their tents on his land. The refugees have no security of tenure or protection against sudden eviction, which is why a certain NGO has been working towards creating a renewable 6 month lease with the landlord in order to prevent evictions and price changes. According to Lebanese law, it is illegal to offer tents or prefabricated shelters to the refugees as it is perceived as encouraging them to settle. Thus, it is up to the refugees to build the structure of their tents, after which the NGOs are allowed to provide plastic tarps to cover the structure, rendering them water 


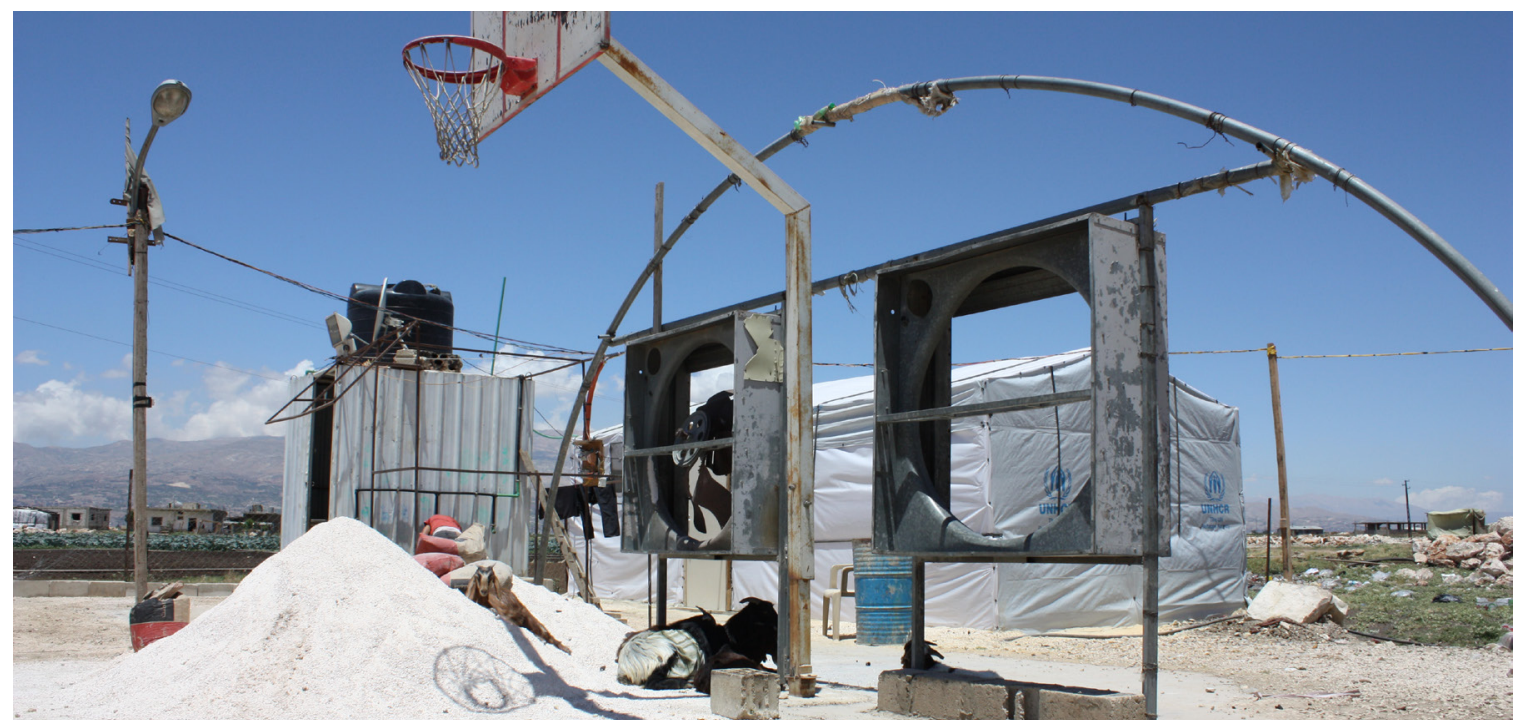

Figure 7. Latrines and livestock in a vacant basketball court, near a refugee camp in Anjar, Lebanon. Photo by author, june 2014.

and wind proof. Other than the wood for the structure, the refugees have to buy concrete and pay workers to pour a foundation for the tent. While they live in poverty, almost every tent has a satellite receiver and a TV monitor to watch the news. They all have electrical power through illegal connections to municipal lines. The inhabitants also have cellphones and internet connection in order to communicate with their families and NGO representatives. Almost every camp has livestock for the production of dairy products and meats.

The most common problems according to the residents are: the toilets which do not have any kind of draining system and overflow regularly, and the quality of water in the tanks, especial- ly for drinking. They also suffer from cold climate and the lack of waterproofing in the tents, which often flood during the rainy season. Although the temperature can go below freezing point during the winter, the tents do not carry any kind of insulation layer. The lack of ventilation is also problematic during the hot summers as the tents often overheat. More than $50 \%$ of the camp's population is underage, and most of these fled the war zones without their families. According to the NGO, the condition of women depends on the size of the camp: they are more secure in small camps as they are surrounded by relatives or friends, whereas in larger camps, women are often subject to sexual assaults and violence with widows and single mothers being most targeted. 


\section{From Camp to Settlement}

According to the Forced Migration Online organization, it is important to acknowledge the difference between the structures of a refugee camp and a refugee settlement ${ }^{6}$. While a refugee camp is an immediate and necessary response in time of crisis, it should gradually and quickly evolve into a refugee settlement that offers a proper living environment.

The main differences between the two structures are the following: In the refugee camp, the freedom of movement is restricted and controlled by the authorities. The refugees rely on relief handout and food distribution while the camp is governed by an external organization or government. The dwellings are in poor structural and sanitary conditions and the camp is overcrowded due to the lack of accommodation. Whereas in a refugee settle-

6 SCHMIDT, Anna (n.d.). FMO Thematic Guide: Camps versus settlements. Retrieved September 17, 2014, from http://www.forcedmigration.org/research-resources/ expert-guides/camps-versus-settlements /fmo021.pdf ment, the inhabitants have full liberty of movement and they are able to engage in subsistence farming or other economic activities. The settlement is self-governed and offers suitable accommodations with an appropriate population density.

All the factors mentioned above are directly influenced by the urban planning strategies applied to the camp. A proper urban plan is one that provides public spaces where the refugees can engage in prosperous economic activities but also a significant amount of semi-public space where the inhabitants can have personal social interaction. The presence of those elements will lead to the full autonomy of the settlement, and eventually, to self-governing. 


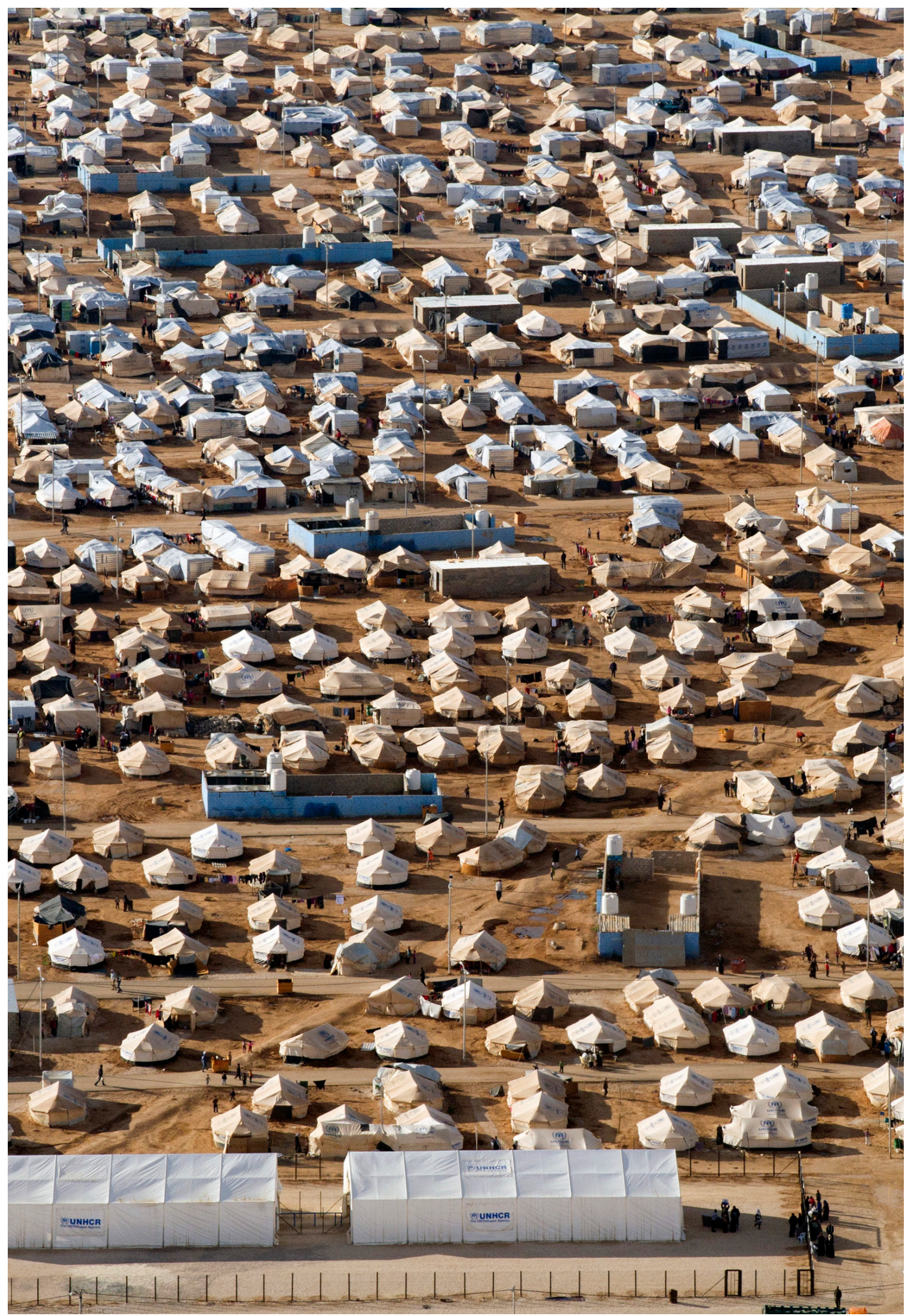

Figure 8. Al Zaatari refugee camp in Jordan. UN Photo/Mark Garten, decembre 2012. 


\section{Built environment analysis}

There is a striking contrast between the traditional building typology and the one that appears in these camps. The construction of shelters doesn't seem to take into consideration any kind of architectural convention nor refer to any cultural standard. There is no urban planning whatsoever, which results in a very chaotic and ill-adapted built environment. Although the settlements act as independent entities, with the inhabitants having the freedom of movement and economic activity, the serious lack of resources and financial means paralyzes the whole community and forces them to live in poverty.

Due to the scarcity of materials and means, the structures are rarely functional. The lack of experienced labor results in very precarious constructive detailing. Nevertheless, creativity is evident in the use and re-use of basic construction materials. This rupture between the traditional architecture and that of the camps could be interpreted as a loss of identity or a transformation of reality.

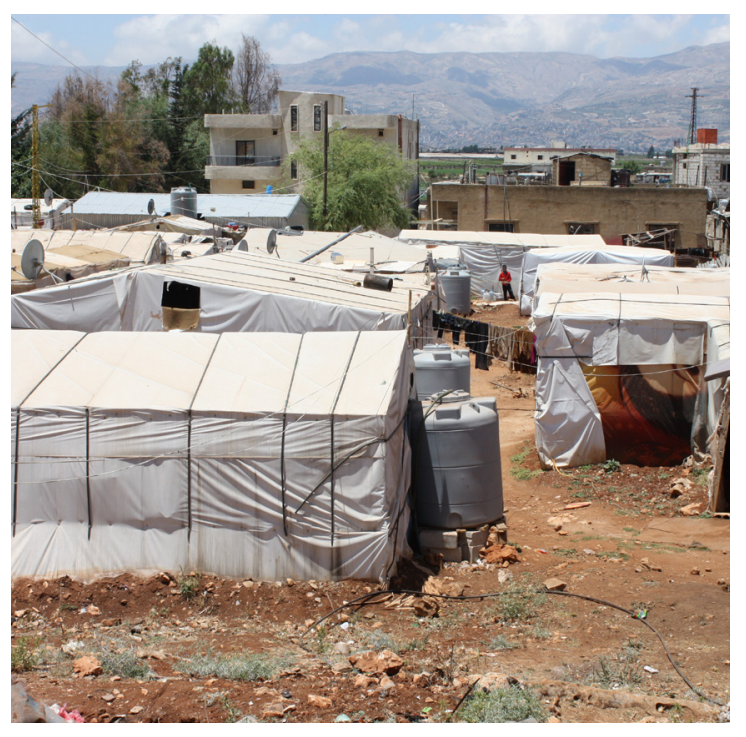

Figure 9. Improvised housing near Anjar. Photo by author, 2014.

In order to build the settlements, the refugees often use recovered materials from construction sites including timber elements of various shapes, plastic tarps, cement bags, tires, fabric, corrugated metal sheets and wire (Fig.10). These resources are usually free or very cheap to buy on the black market. The foundations of the tents are usually made of a concrete slab that is poured on site, and delimited by concrete blocks. The tent structures are made of timber covered with plastic tarps for water-proofing. The camp infrastructures however lack multi-purpose spaces that would otherwise allow for the production of goods and services, in order to gain higher levels of autonomy. 

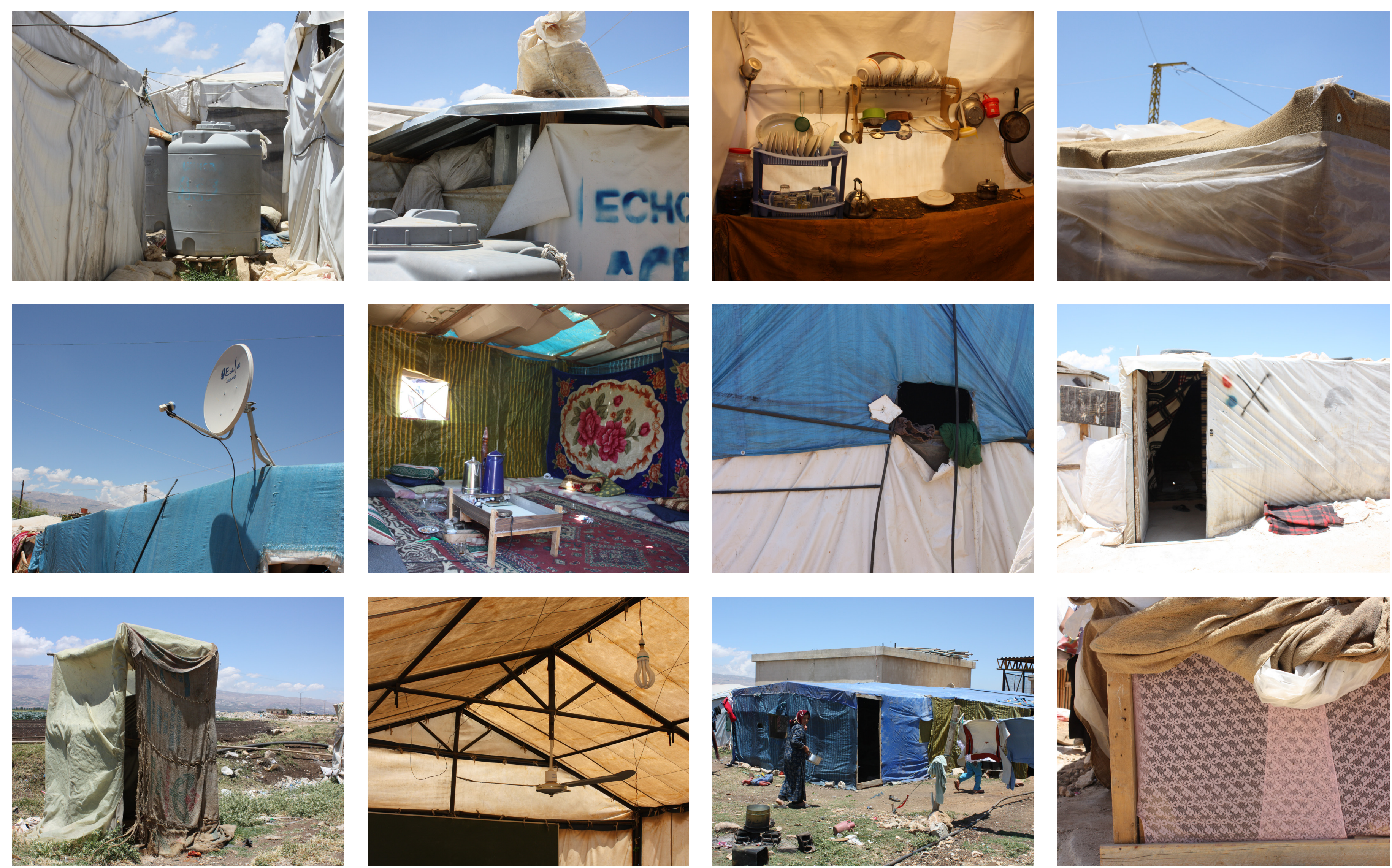


\section{Frederick Cuny's cluster model}

Frederick Cuny was an American disaster relief specialist who was active in many humanitarian projects around the world from 1969 until his disappearance in Chechnya in 19957. He worked extensively on ideas for refugee camp planning and design, taking into account political realities and cultural mores.

Whereas most camps at the time were designed in a grid, with multiple families housed in military-style barracks, Cuny's design housed victims in single-family tents clustered around open common spaces. Each cluster had its own latrines, cooking areas, and other basic services. With the tightly knit clusters Cuny encouraged ownership, thereby preventing the camp's infrastructure from being over-burdened, which in turn would help prevent the outbreak of disease and allow for better management. He tested his idea in Nicaragua, in 1972 following an earthquake. While security issues plagued other camps, at Cuny's camp, industries and self-help organizations sprouted instead. Moreover, it was estimated that the camp cost 40 percent less to operate than its counterparts.

7 Architecture for Humanity. Design Like You Give a Damn: Architectural Responses to Humanitarian Crises. New York: Metropolis books, 2006, p.33 


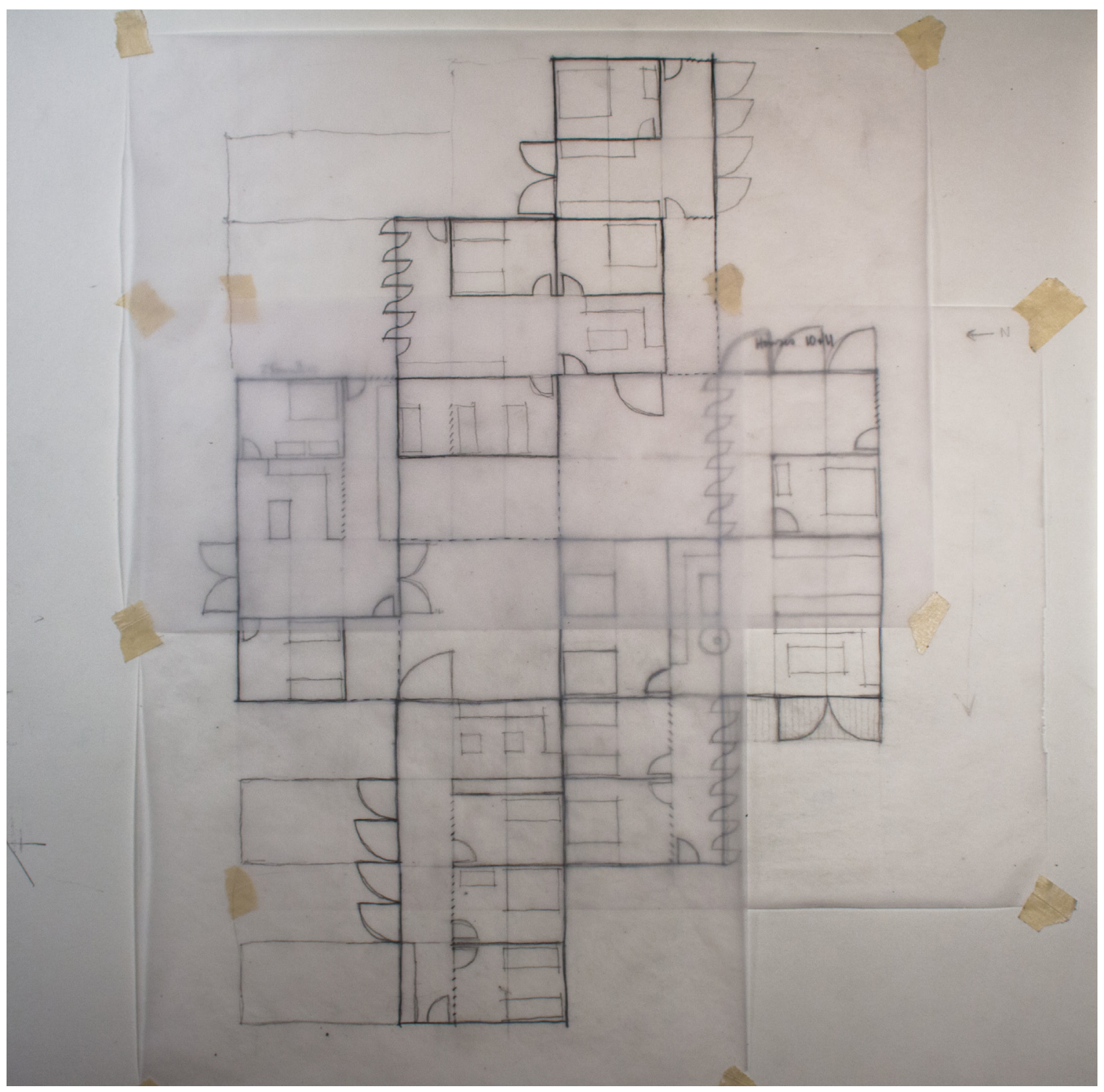

Figure 11. Dwelling cluster composed of modular housing and shared courtyards 


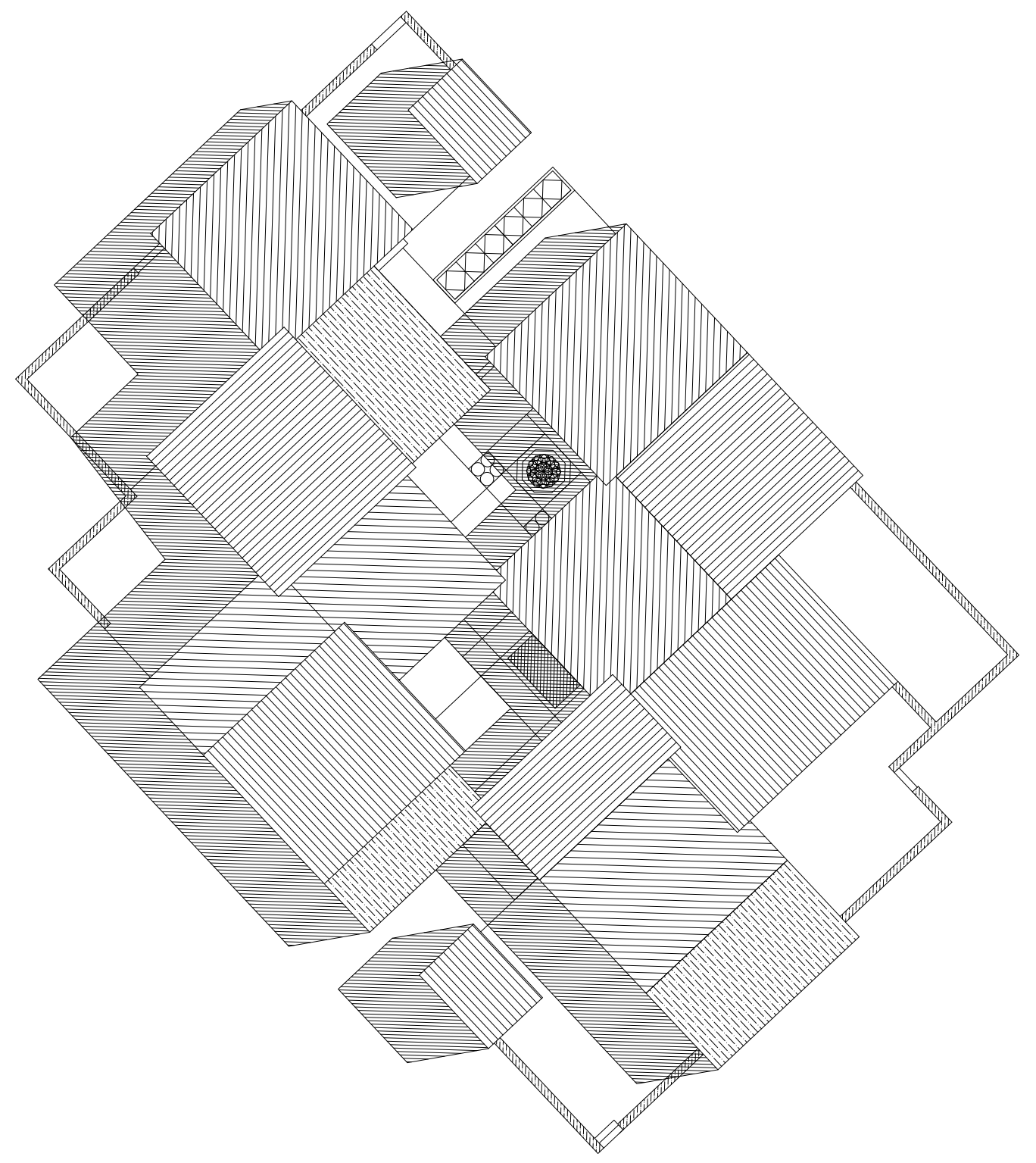

Figure 12. Roof plan of dwelling cluster 


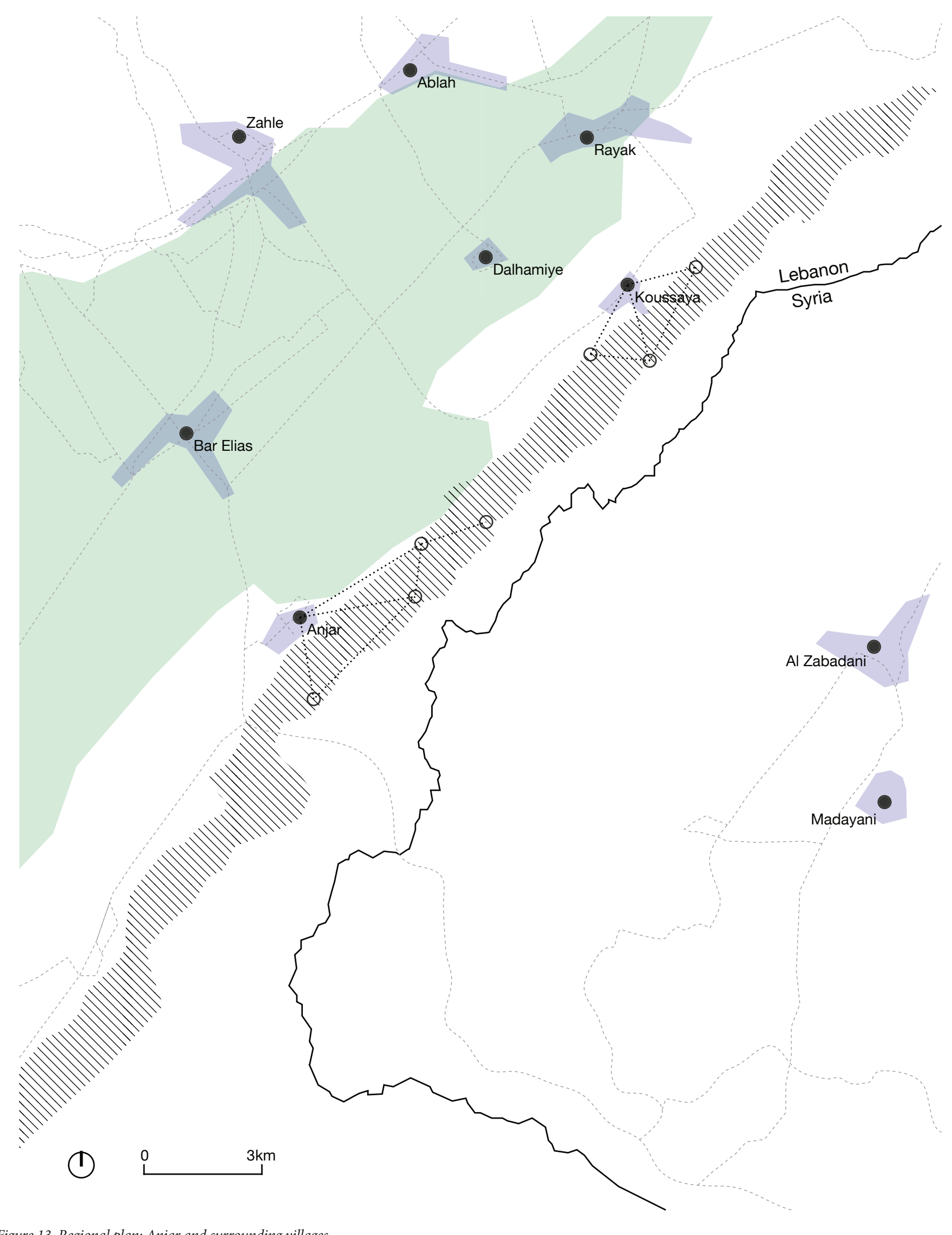

Settlement Area: delimited on one side by the rocky mountain chain and the other side by the agricultural lands and rural developments.

Agricultural lands: being the main economic activity in the region, the agricultural fields occupy most of the valley's lands. Its fertile soil and water supply provides a hospitable environment in a mainly desert landscape.

Existent infrastructure: Electricity, water and sewage systems are mainly implemented in and around existing village, but they have the potential to extend towards future settlements.

Transportation network: These streets link the many small villages of the area with one main road crossing the Syrian-Lebanese frontier

Syrian-Lebanese frontier: This political separation dates back to the British and French colonization era. However, the absence of a physical barrier along this line causes for a blurred border, intertwined with the sinuous topography. Cultures and social identities overlap on both sides of the frontier.

- Refugee settlements: the implementation of refugee communities in the vicinity will create new nodes in the existing urban network, further developing the regional activity. 


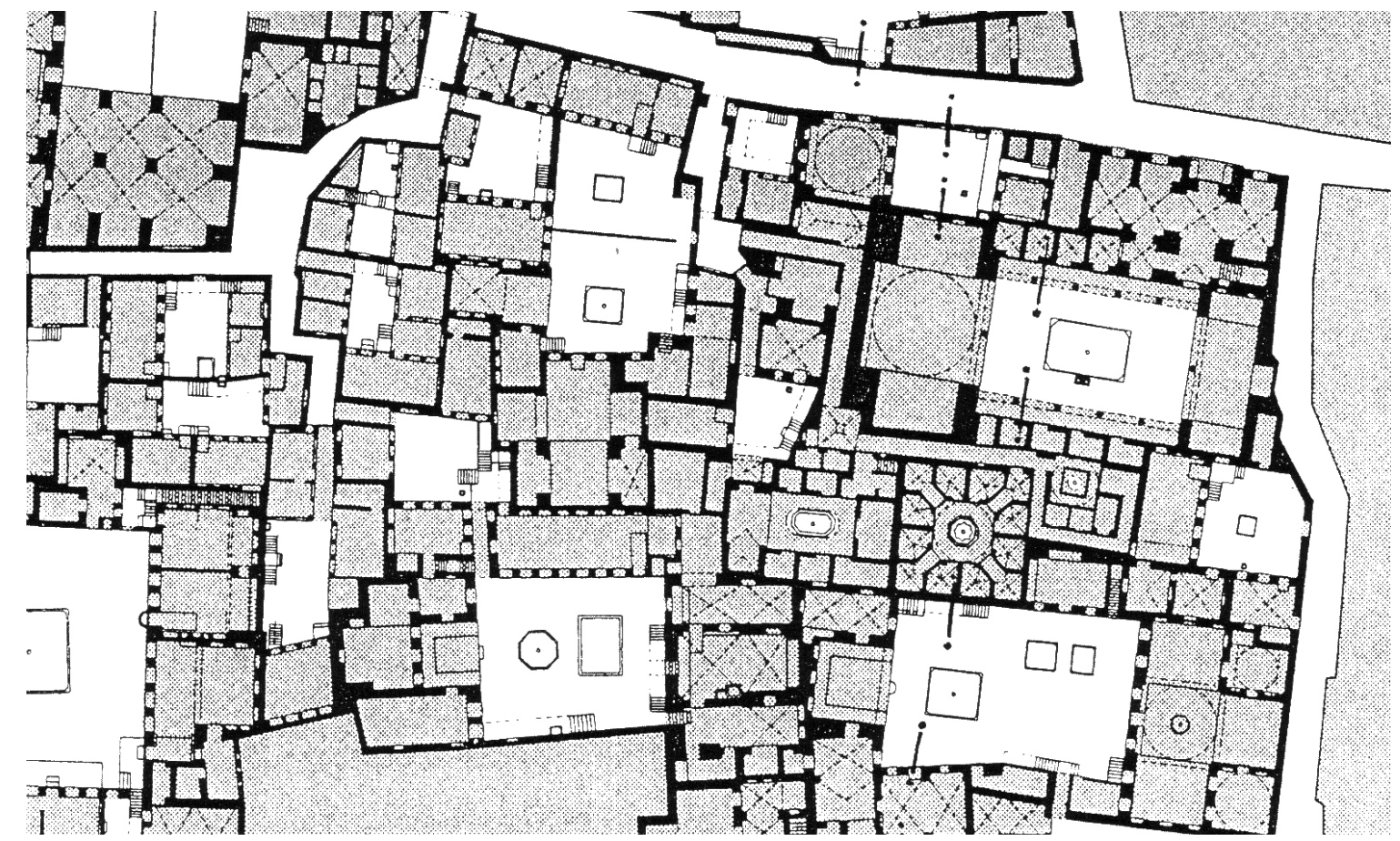

Figure 14. Courtyard houses in Aleppo, Syria

\section{Cultural Reference}

This project aims to find inspiration in both the Syrian architectural heritage, which relates to the culture's collective memory, and the creative constructive approach typical of the camps. During the research phase, we were able to detect a number of architectural properties relating to each of these typologies.

The first set of drawings (Fig.15) is based on photos of traditional architecture in Damascus, while the second set represents constructive methods employed in the improvised camps.
In the first case, the strong presence of courtyards and public squares seems to indicate an architectural culture that revolves around shared spaces. A semi-closed circulation acts as a transitional space in between the outdoor and indoor. In the camps, the diversity of materials and the layering allow much more versatility than traditional concrete walls. It is also interesting to note how easily technological systems, such as satellite dishes, can be integrated into rudimentary shelter structures. 

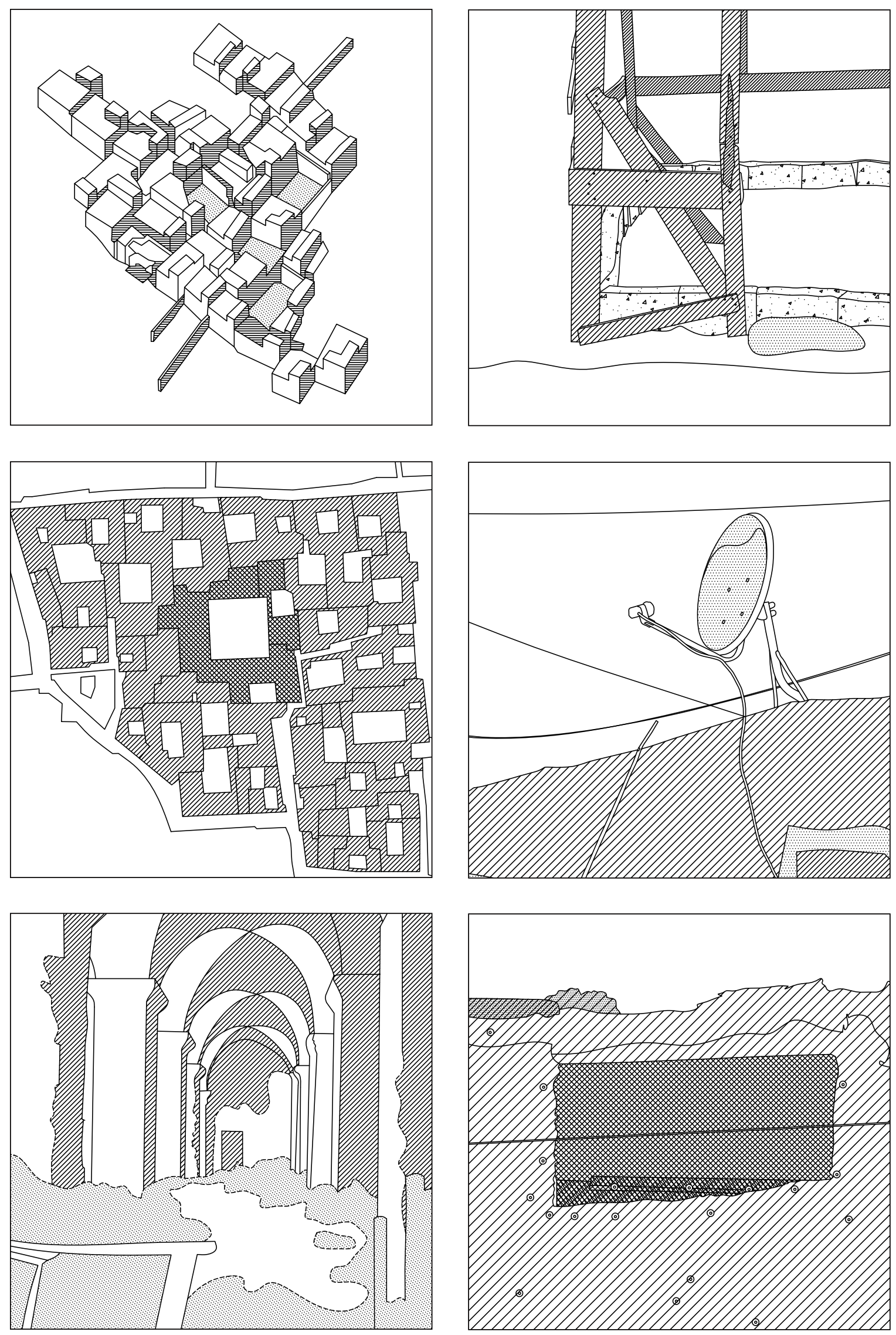

Figure 15. Digital Sketches of traditional Syrian architecture (left) and refugee camp architecture (right) 


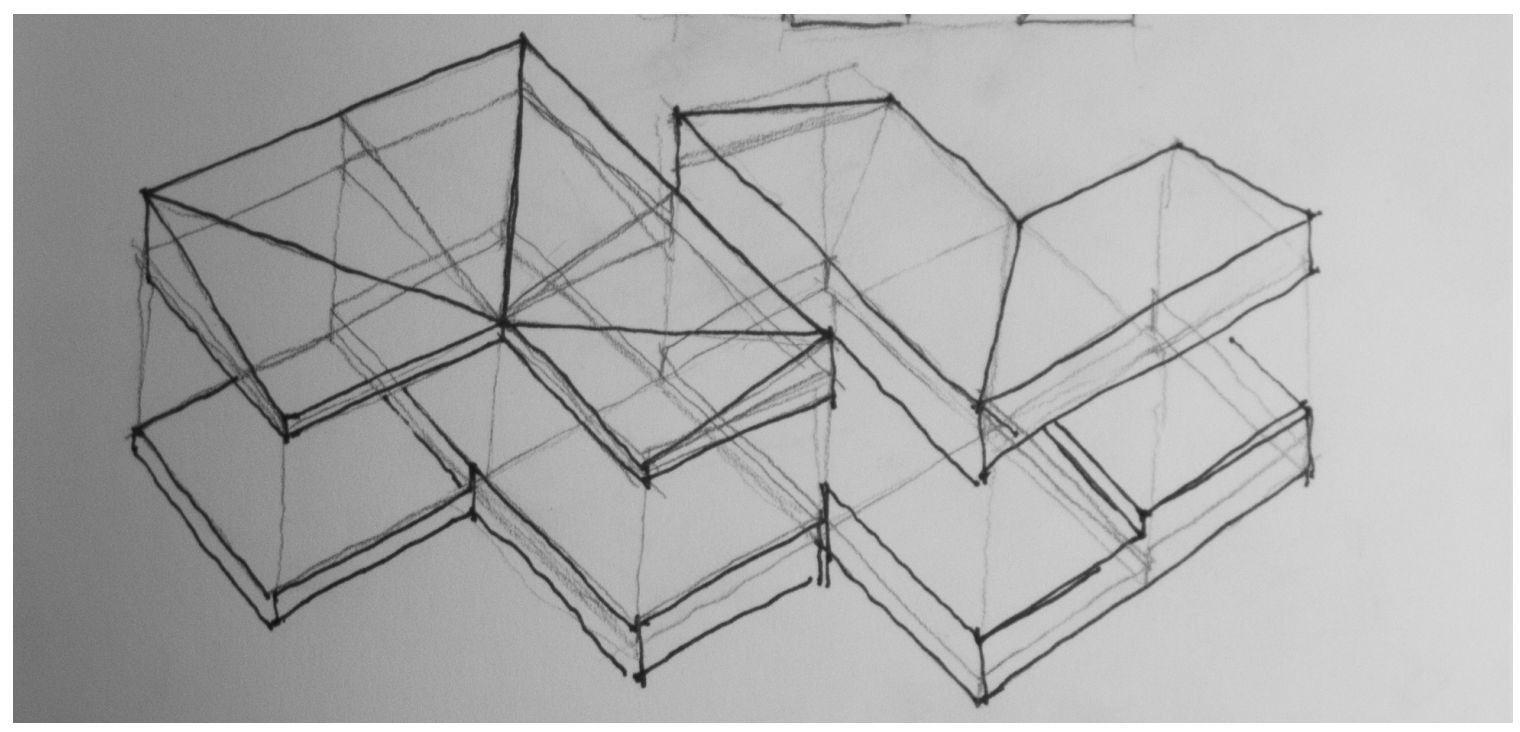

Figure 16. Volumetric study of housing unit

\section{The cluster model and urban planning}

In order to provide a functional built environment, the general layout of the settlement will be presented in the form of clusters, each composed of 6 housing units. The structures will be disposed in an offset position as a way to create interstitial spaces that could serve as serviceable outdoor spaces (Fig.21). This disposition will also reinforce security inside the settlement by giving each dwelling a direct view over their neighboring units. The presence of the semi-public spaces will provide a familiar urban structure as it is reminiscent of the traditional courtyard house composition. The shared walls between two dwellings offer the possibility of a direct connection, further facilitating customization.
The combination of terraced platforms and shifted courtyards provides a dynamic landscape extending diagonally through the cluster. This axis creates a circulation flow at the heart of the development and energizes the social interaction inside the cluster. The semi-public spaces can be accessed by two subtle entrance points at both ends of the development. The integration of a water collection system, through the implementation of water basins inspired by traditional Syrian fountains, serves as a source of non-potable water to the surrounding houses (Fig.17). The successive ponds are embedded in the ground, collecting the rain water running down the mountain slopes. The inclined roof structures will also canalize the 


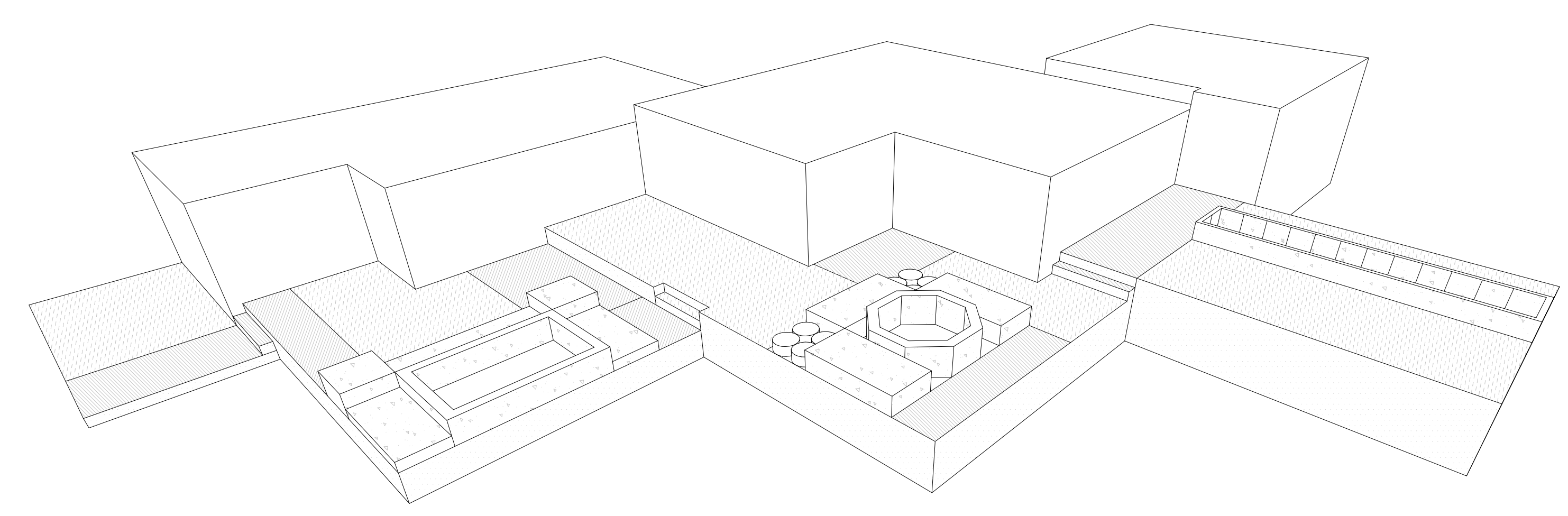

Figure 17. Terraced courtyards composition
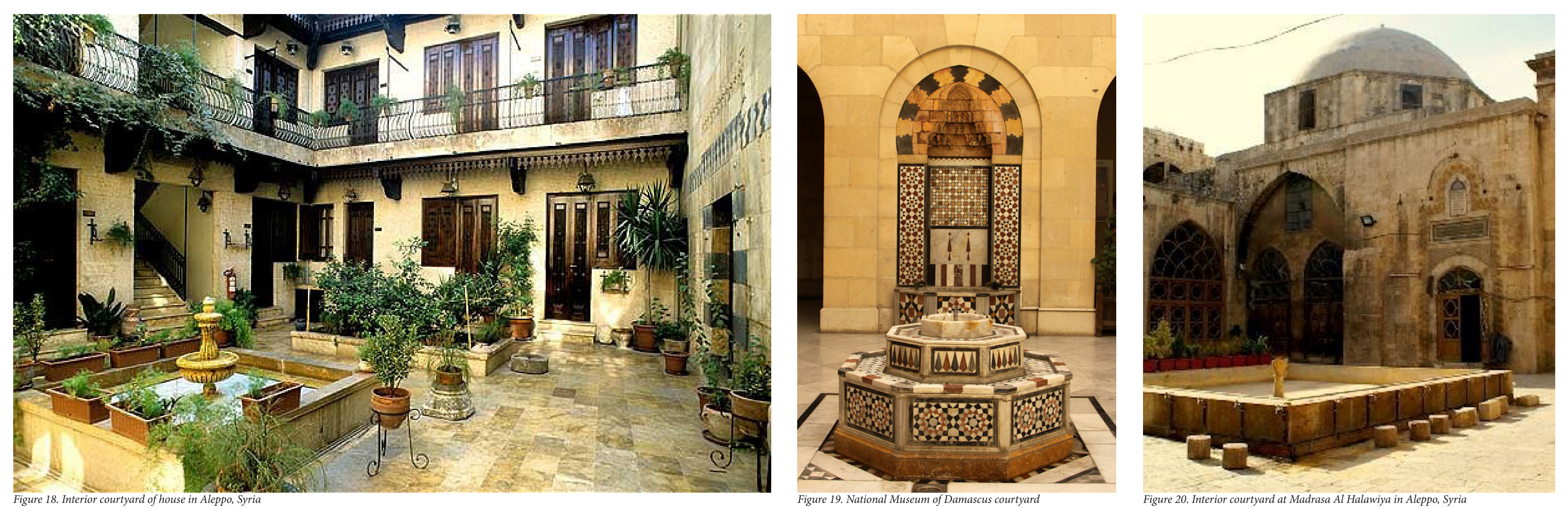

Figure 20. Interior courtyard at Madrasa Al Halawiya in Aleppo, Syria 

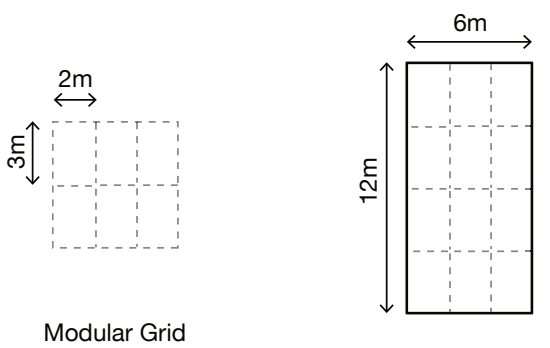

Single Dwelling

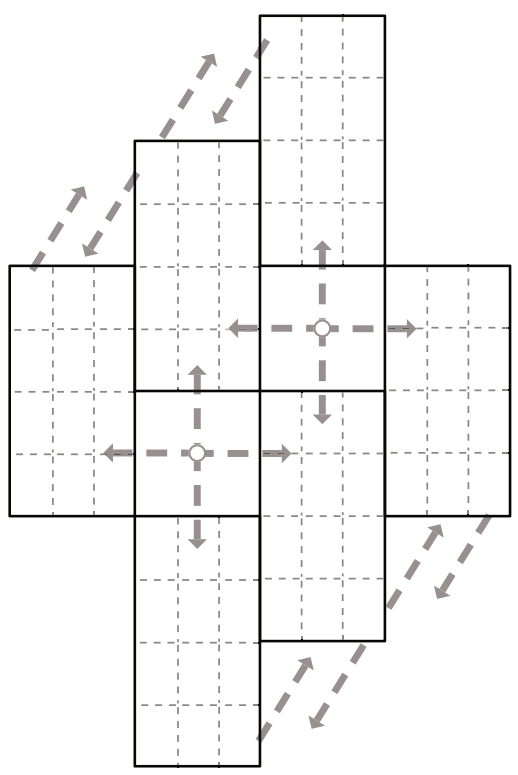

Housing Cluster

Figure 21. Diagram of housing cluster structure

water towards the ponds for subsequent use.

Set up around the water stations, the courtyards come alive through the implementation of cooking, working and recreation areas.

On a larger scale, the camp will be composed of a number of clusters, to which will be added modules serving as cultural spaces, schools or medical clinics if needed (Fig.22). The sanitary installations can be further developed as an autonomous waste recovery system in order to provide water for irrigation and compost for fertilization. The general layout will create pathways in between the built areas, serving as circulation throughout the settlement. These pathways have the potential of evolving into a public market as has been observed in larger camps like the Al-Zaatari refugee camp in Jordan (Appendix A). A large scale water canalization system can be dug into the ground along the mountain slope in order to prevent overflowing during the rainy season. The planned settlement is approximately the size of the visited camps, and will house approximately 108 people in 18 dwellings. 


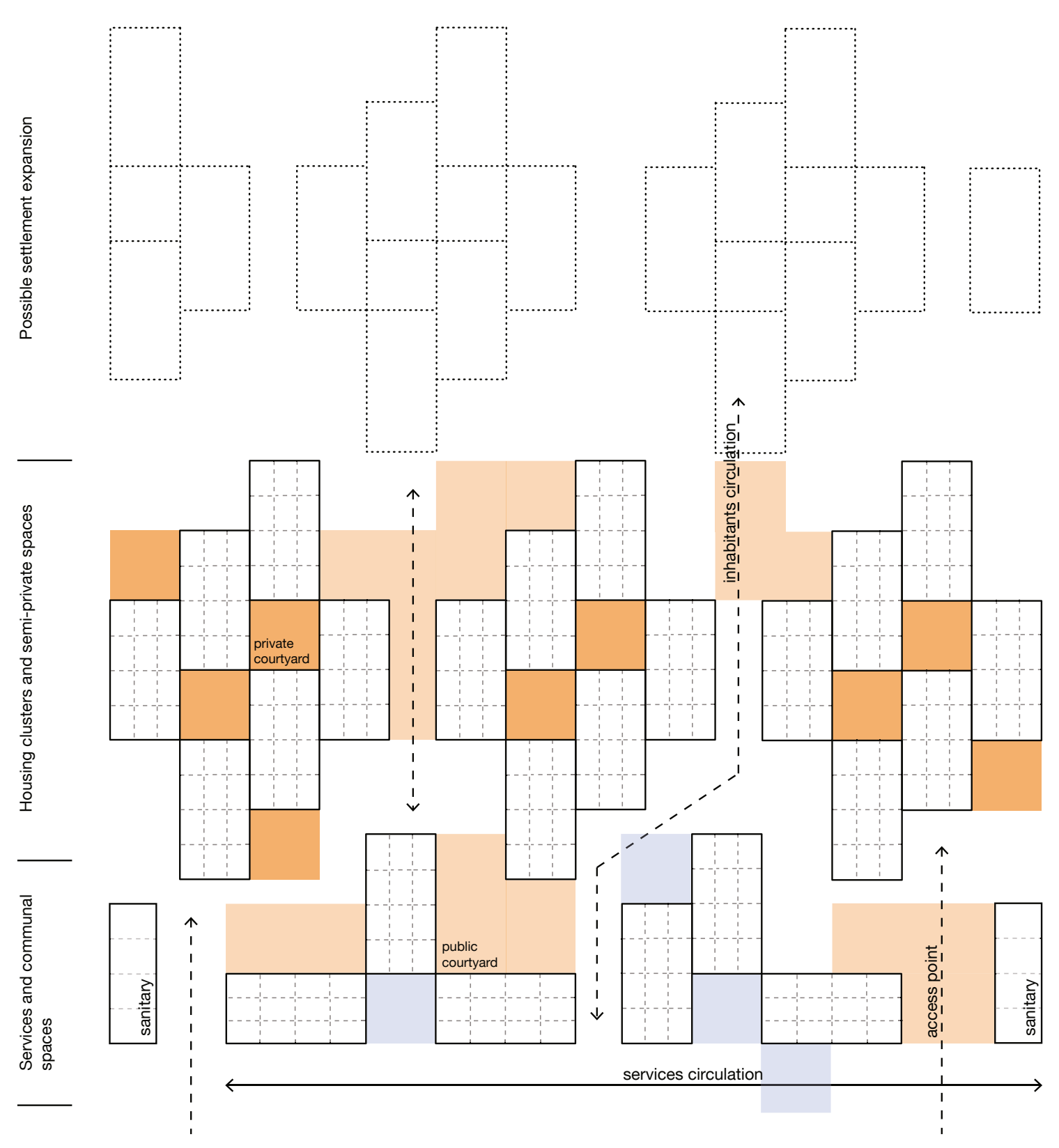

Figure 22. Refugee settlement layout 


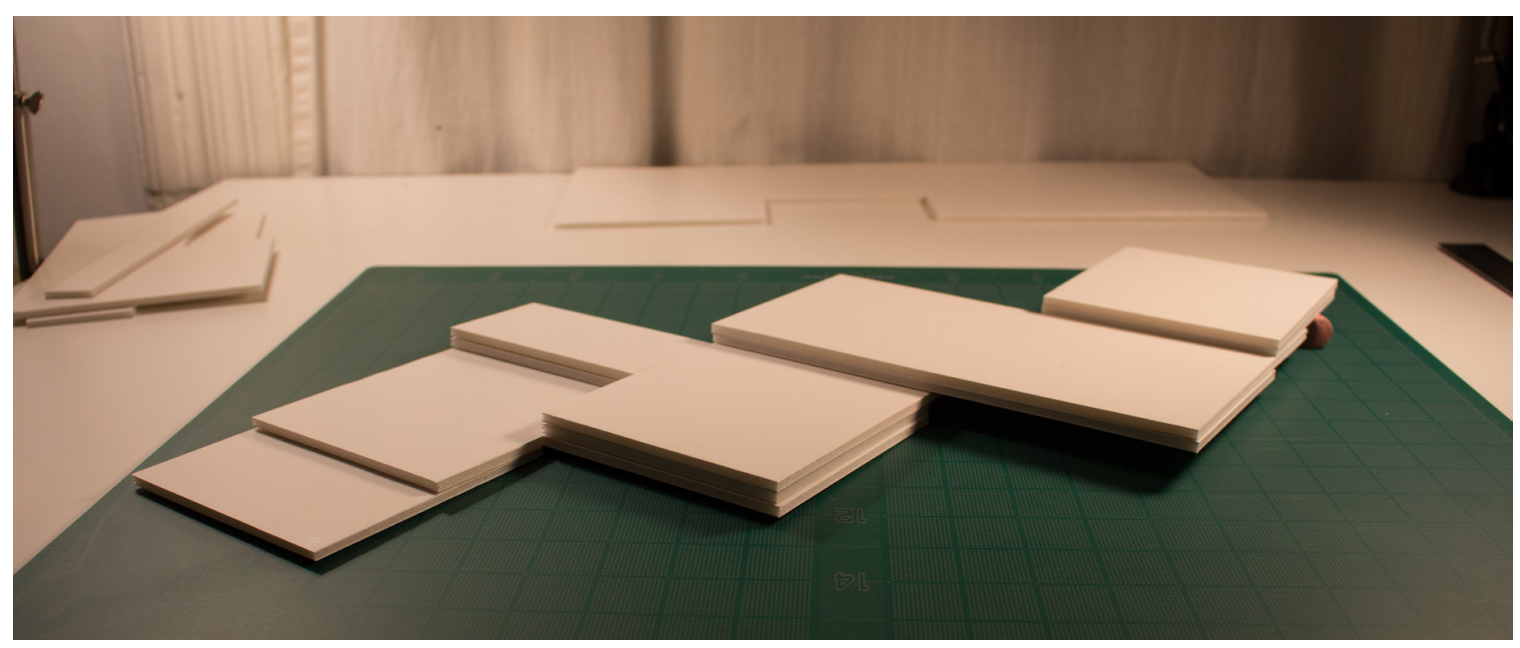

Figure 23. Physical model of dwelling foundations

\section{Basic prototype and modular adaptation}

The most basic element in the structure of the settlement is the single dwelling unit. The rectangular structure is divided into 12 substructures in order to allow flexibility in form and function. It will also allow the inhabitants to build the shelter in several stages according to their financial means. This subdivision will provide a better adaptation to the topography by building the shelter in leveled platforms. Composed of $2 \times 3 m$ units, the final dimensions of a single dwelling are $6 \times 12 \mathrm{~m}$ for a total area of $72 \mathrm{~m} 2$.

The single shelter is meant to house from 6 to 8 people, either as a single family dwelling or a shared residence. Considering that the refugee population is often composed of separated family members in a non-tradition social structure, the subdivision of the space is critical to offer the appropriate privacy to each inhabitant or group. Besides the primary functions such as kitchen and living spaces, a portion of the shelter may be converted into a shop for the sale or exchange of goods. Each dwelling will also have the choice of assigning a portion of their land for livestock or agricultural activity, thus helping them gain relative financial autonomy.

In order to develop a sensible solution, we created a hypothetical community composed of 108 fictional characters based on known de- 
mographics and probable scenarios. Each of them was attributed an identity defined by their age, background, occupation and other relevant information. Each fictional inhabitant was then randomly assigned to a dwelling, thereby creating 18 distinct families.

The flexibility of the proposed model can be tested through a series of plans adapted to each specific social situation. The proposed general plan represents 5 different dwellings sheltering families of different compositions. These groups range from an all-female household of three to a large double-unit household of 11 individuals of all ages and professional skills. Thus the architectural plan develops on the basis of the group's social dynamic, all the while taking into consideration their individual objectives. The largest household combines two units in order to offer four bedrooms, a large communal area, a studio space for an electronic repair shop, as well as two private patios for farming activities (Fig.24). In contrast, the smallest dwelling is composed from half of a regular unit and contains one bedroom, one small kitchen/living room area and a narrow strip for commercial usage (Fig.25). 


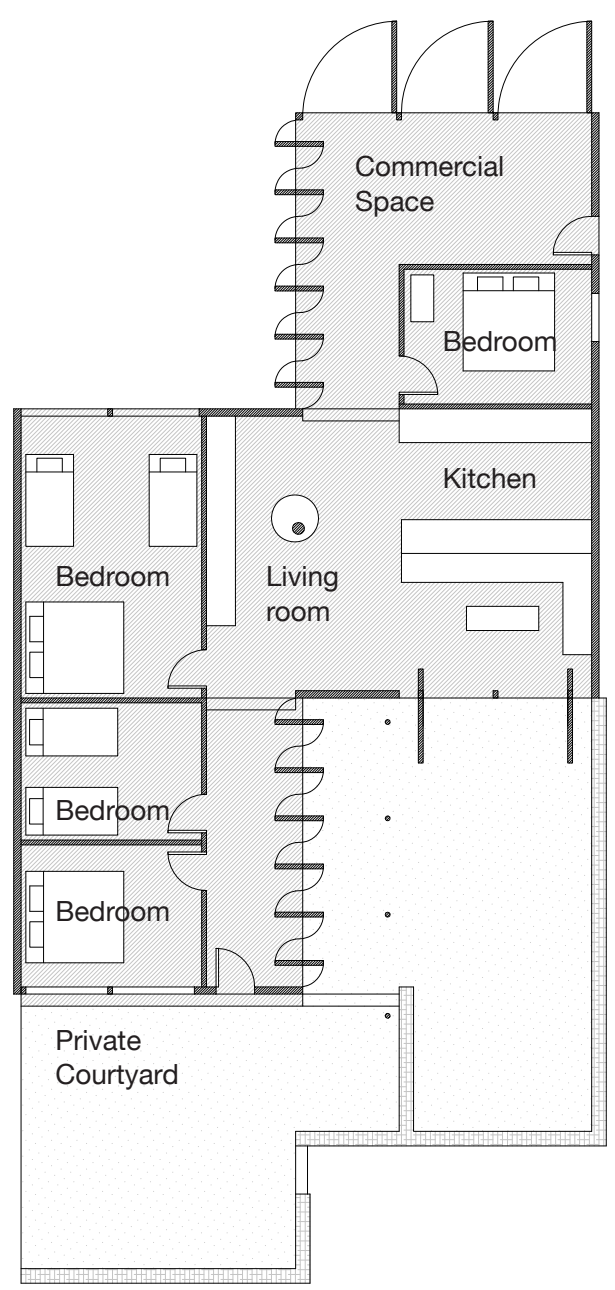

Figure 24. Household no.1 plan
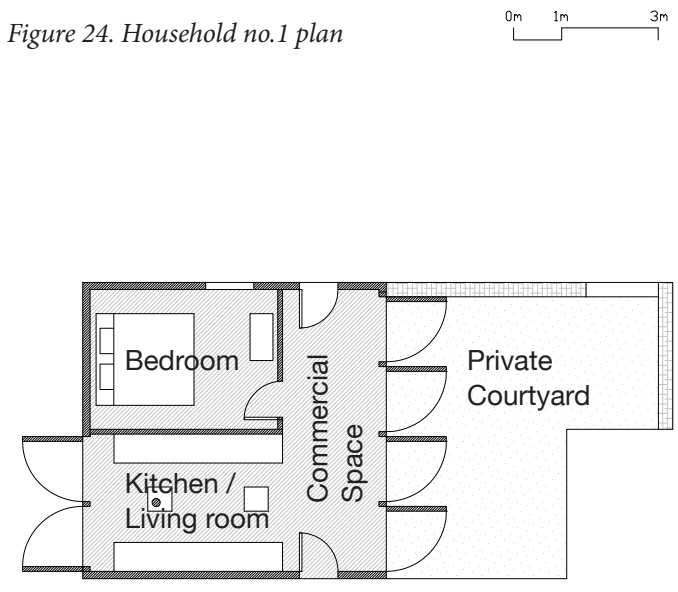

Figure 25. Household no. 5 plan

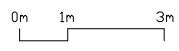

\section{Household no.1 11 people}

Family A

Man, 41 years old, employed in agriculture

Woman, 30 years old, employed in agriculture

Boy, 1 years old

Family B

Man, 52 years old, unemployed, skilled in electrical tech. Woman 53 years old, unemployed, skilled in agriculture

Boy, 14 years old, employed in agriculture

Boy, 5 years old

Girl, 18 years old

Girl, 7 years old

Girl, 4 years old

Girl, 3 years old

\section{Household no.5 3 people}

Woman, 28 years old, employed in a factory

Woman, 47 years old, unemployed

Girl, 14 years old 


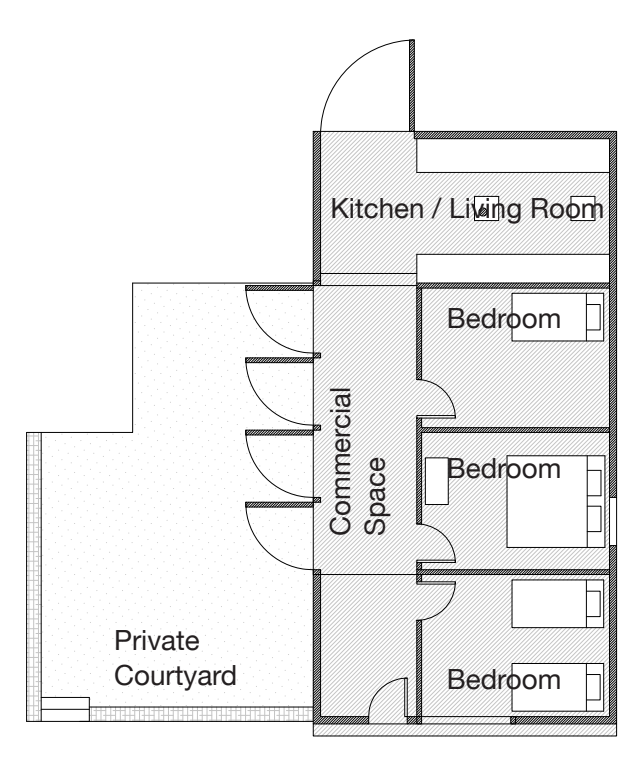

Figure 26. Household no.2 plan
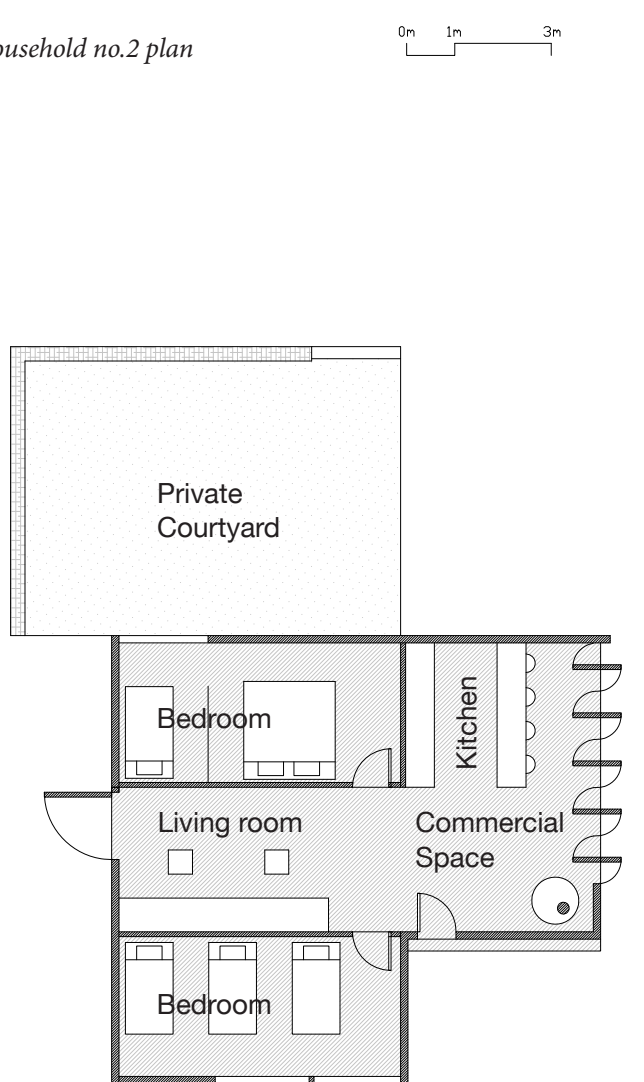

Household no. 4

\section{6 people}

Man, 48 years old, employed in sugar factory

Woman, 48 years old, employed as domestic worker

Girl, 13 years old

Girl, 12 years old, employed in agriculture

Boy, 8 years old

Boy, 1 year old

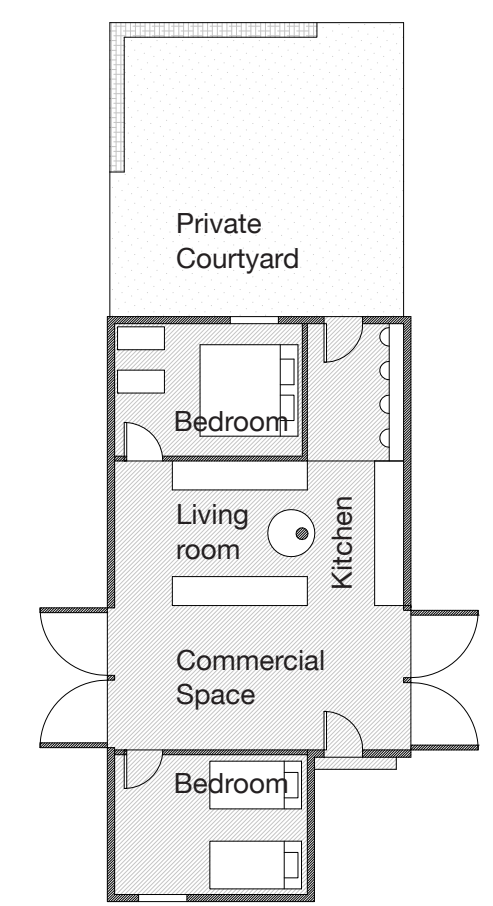

Figure 28. Houschold no.3 plan

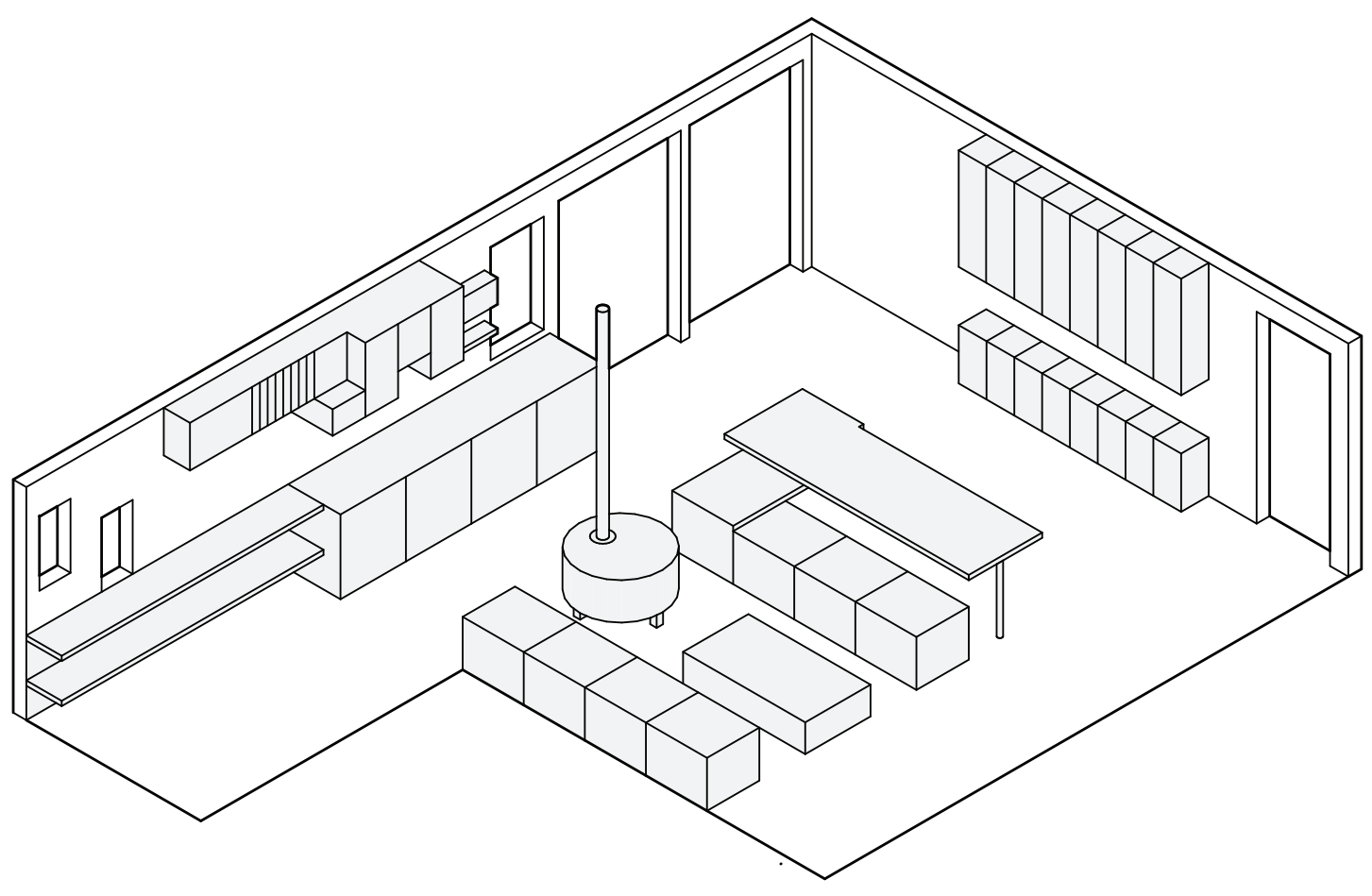

Girl, 2 years old

Boy, 1 year old 


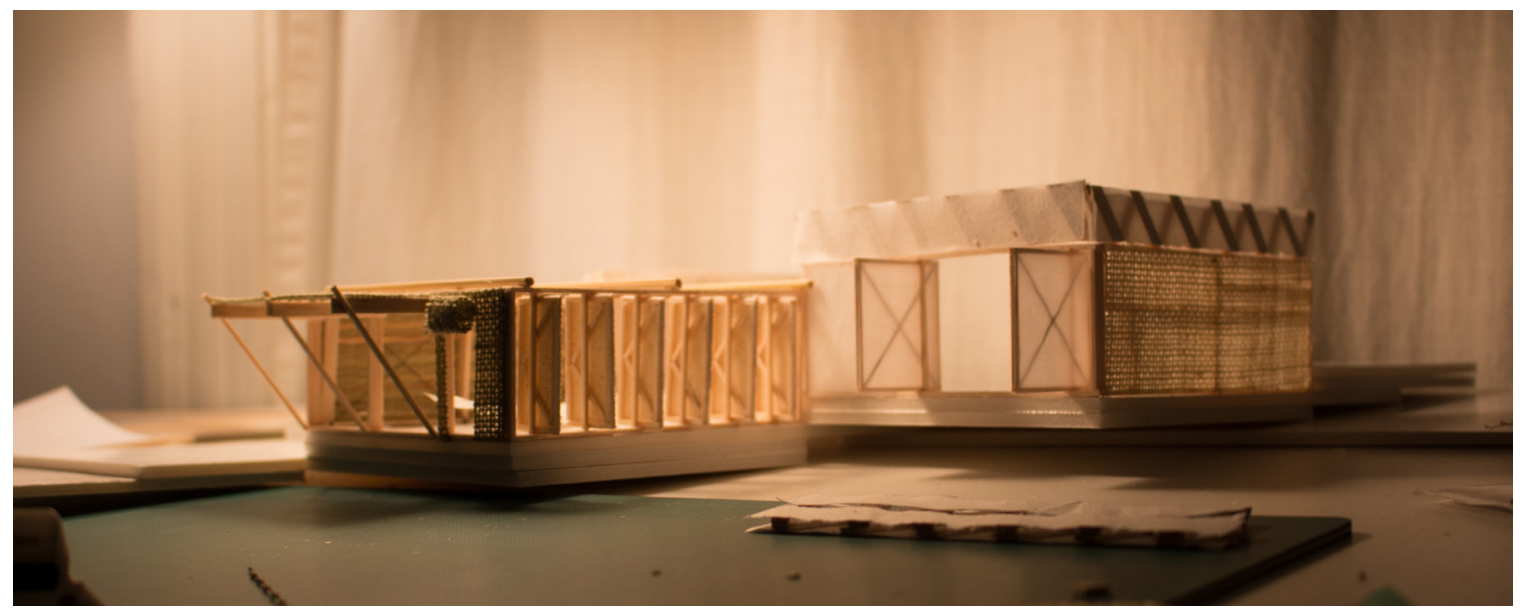

Figure 30. Physical model showing partial construction of a housing unit

All the dwellings designed in the master plan offer an appropriately sized kitchen, living room and bedrooms. They also offer a direct access to both a peripheral private patio and a set of central communal courtyards (Fig.24 to 28). The absence of private bathrooms in each house implies minimal infrastructural development inside the cluster as it will only need a water delivery system and electrical connection. Instead, semi-public latrines are placed at each end of the cluster and can be easily accessed through the courtyards (Fig.31). The envelope treatment and structural composition allows for a highly permeable indoor-outdoor separation, with large rotating, sliding and tilting panels. These openings offer the inhabitants the possibility of extending the interior spaces to the outdoors during the summer season, thus expanding the inhabitable spaces (Fig.30). Unlike the unmovable structure of the exterior walls, the interior partitions are non-permanent and lightweight, allowing for a reorganization of the space when needed. Thus, the complete liberty of the architectural layout endorses the essential concept of modularity.

Although the formal solution can be represented in a single prototype design, its flexibility sets it apart from other generic models, like the prefabricated caravan or the emergency tent, which lack sensibility toward personalization. Combined with an easily dismountable structure, these units will have the potential to form and transform with time and according to the needs of their inhabitants. 


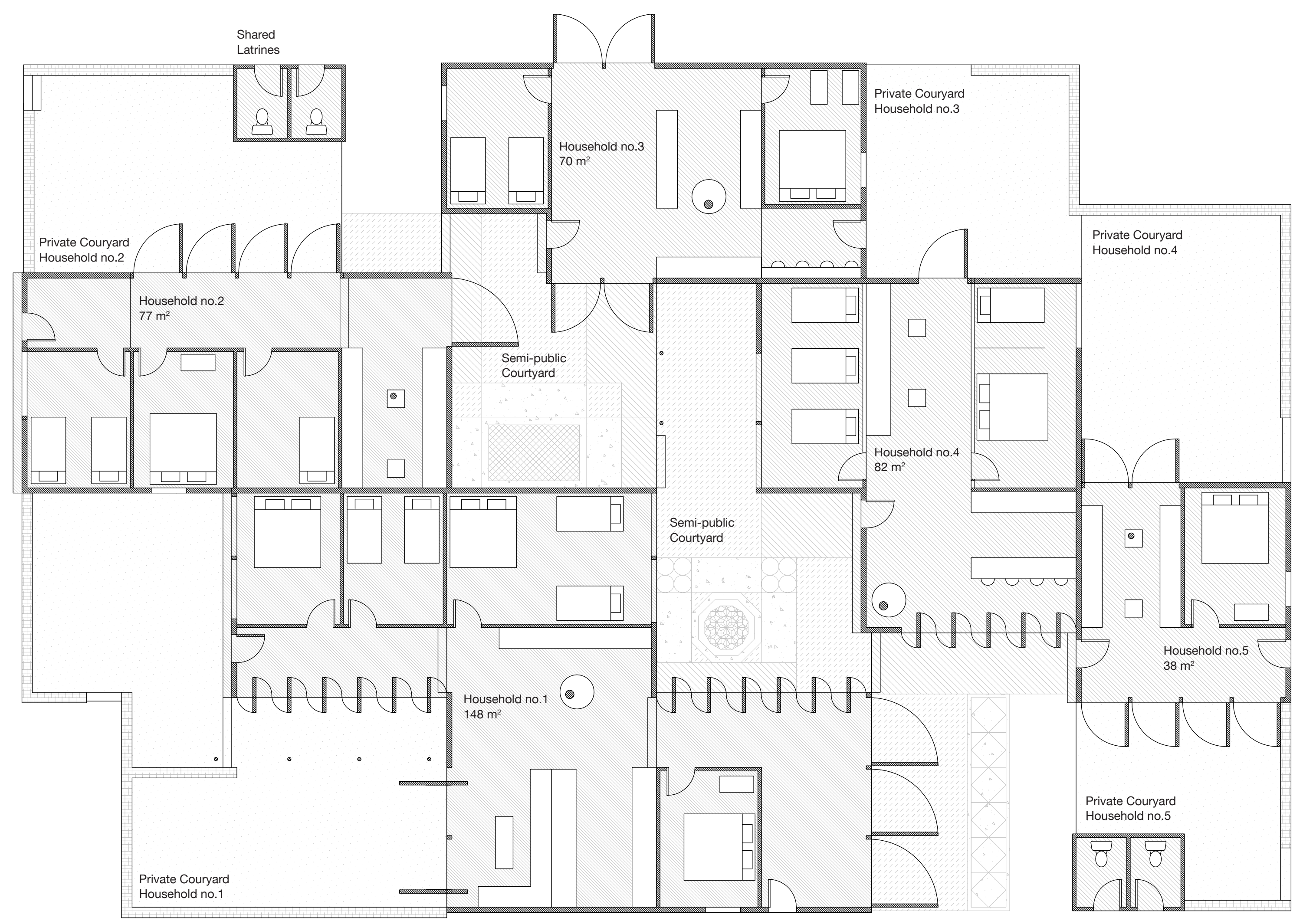




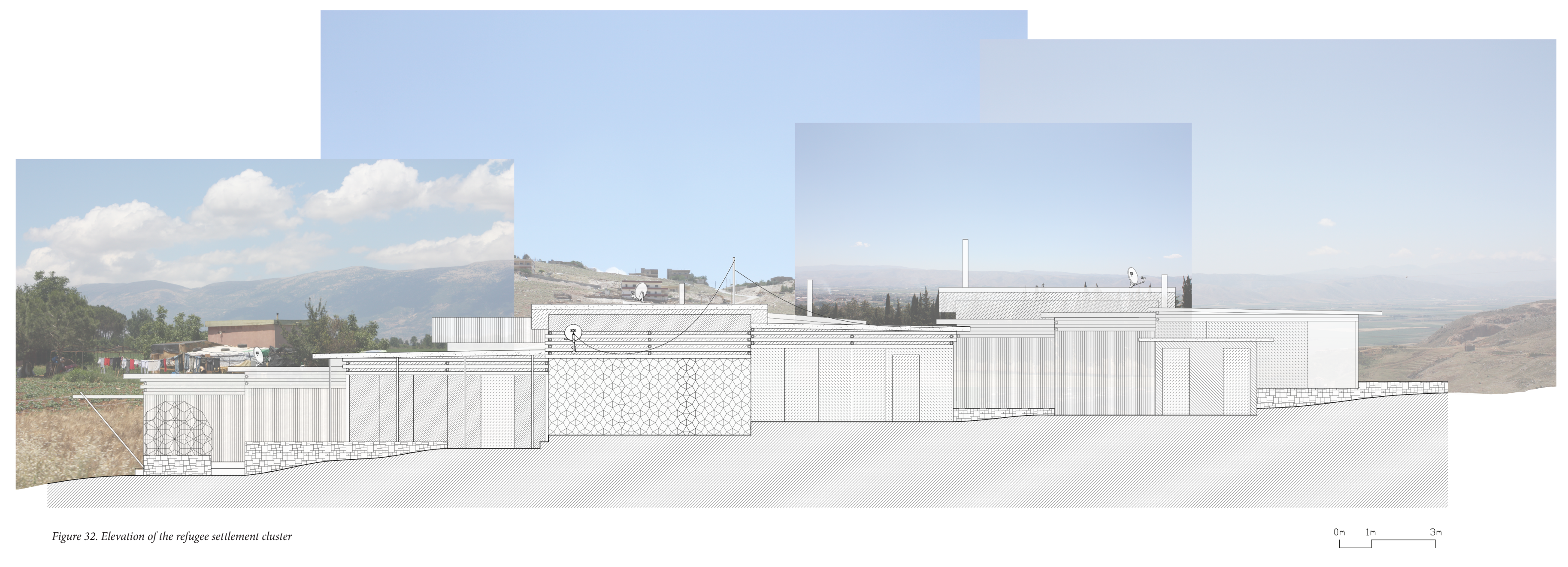




\section{Constructive detailing /physical model}

exploration

The basic materials used for the structure are: concrete blocks, timber and fabric reinforced concrete tubes. The shelter foundations will be composed of multiple small retaining walls made of concrete blocks, thus creating a multi-level dwelling. This structure will allow the settlement to be built along the eastern slopes of the Anti-Lebanon Mountains where most of the displaced population seeks refuge. The platform structure will also prevent the accumulation of stagnant water inside and around the dwellings as well as provide a dry footing for the houses during the rainy season. The main timber frame structure can be introduced deep into the foundation wall, and the blocks filled with mortar for solidification. The envelope can then be applied to the wall structure, both on the interior and the exterior, as well as integrate a removable insulation layer made of either organic or synthetic material. Objects such as sand bags, hay blocks or blanket can be used. The whole framework would be topped by a roof structure made of light weight concrete tubes. Those elements can be produced on site by dipping textile in a concrete mixture, and molding it on a tubular element like a PVC pipe. The textile reinforced concrete proves to be a very adequate material as it is very cheap to produce and has incredible physical proprieties: light, solid, air tight, water proof and resistant to extreme temperatures. Most of these joints can be attached with either metal wire or rope (Fig.33).

Once a solid frame has been built, the process of material exploration can be reintroduced as a creative solution responding to the lack of traditional building materials. The project developed in this thesis does not dictate the use of a specific material but rather exploits the potential of non-traditional elements, along with their diverse physical and technical properties. Adaptive and improvisational methods can make use of material such as straw, sticks, corrugated metal, plastic tarps, burlap, textile, PVC pipes, rope, clay, cement, wire and other materials in order to create an efficient and solid envelope. The combination of these el- 


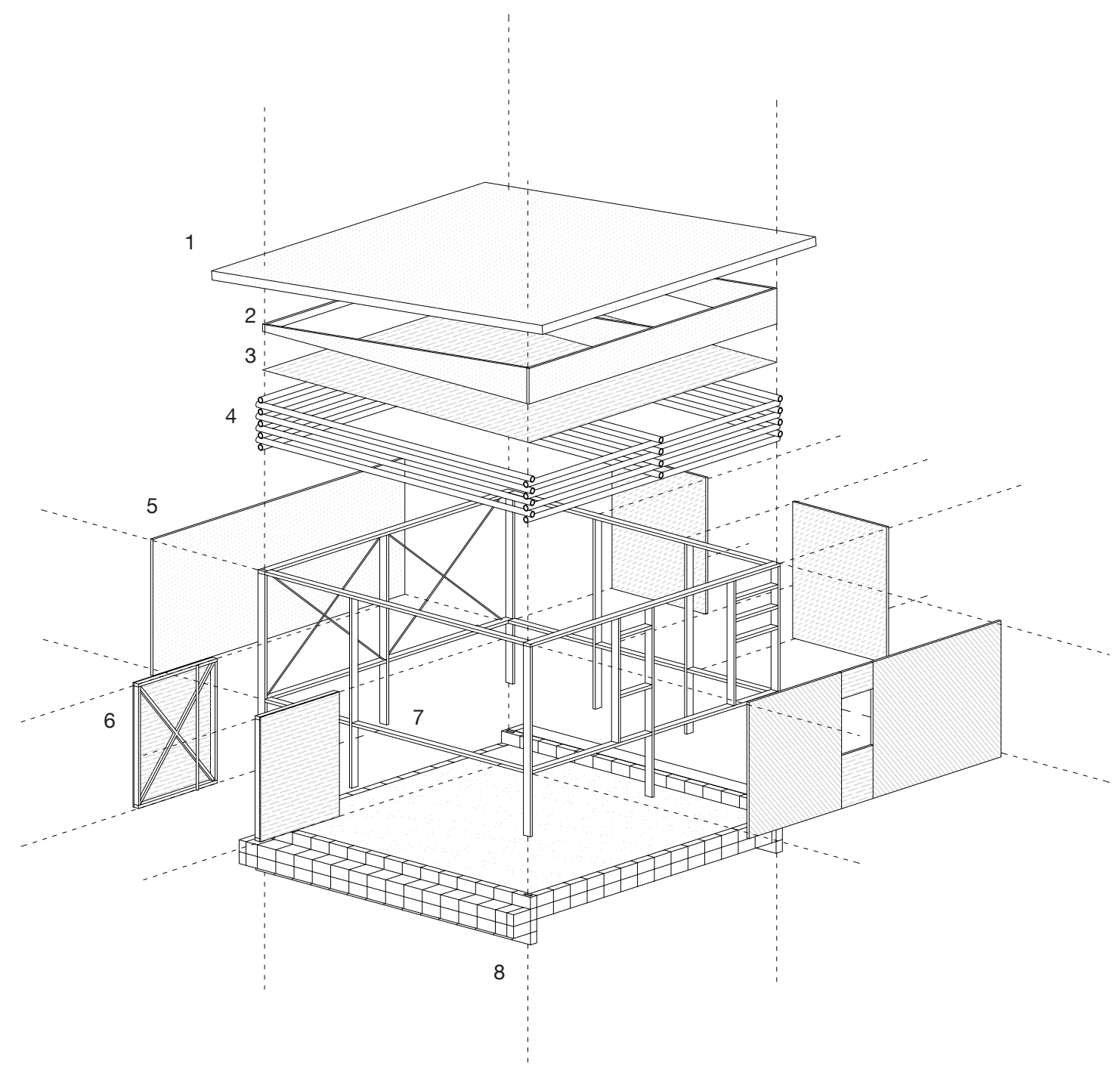

Figure 33. Exploded axonometric view of dwelling

\section{List of construction materials}

1. Sandwich roof panels composed of high strength material, $\quad 6$. Rotating panels help connecting the interior living spacsuch as corrugated metal or plywood, and organic thermal es to the outdoor courtyards, thus encouraging communal insulation. activity.

2. Slope structure creates inclined roofs for water collection.

7. Timber structure is built out of loadbearing material in 3. Waterproof surface intended to prevent leakage and maxorder to provide strength and stability to the constructions. imize protection against natural elements.

8. Retaining walls are made of concrete blocks molded on

4. Structural concrete tubes are easy to assemble and light- site. They act as a foundation for the house though multiweight. They can be built on site and bounded with rope. ple retaining walls and terraced levels along the mountain 5. Multi-layer skin is adaptable to climatic conditions and slope. seasonal changes. 


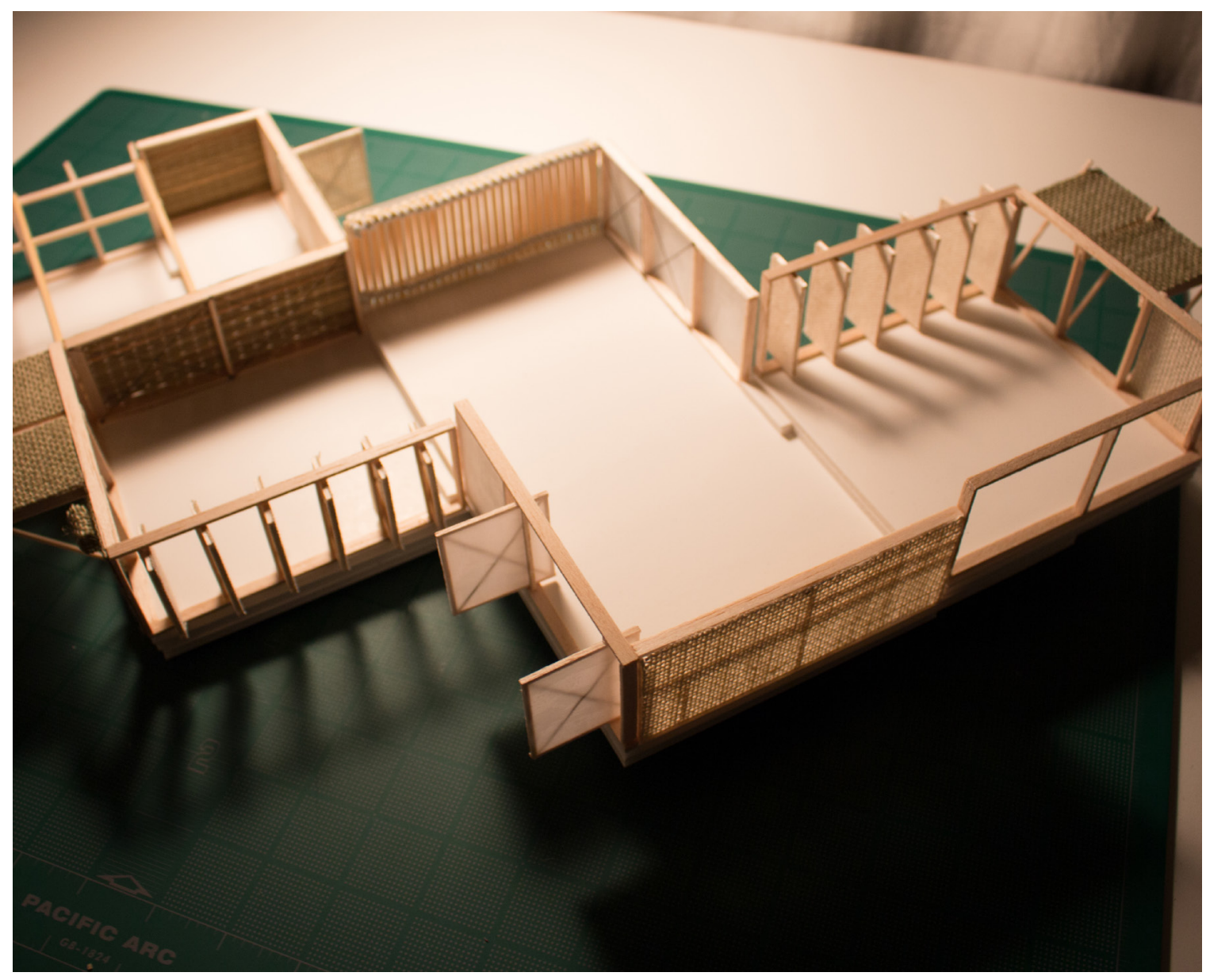

Figure 34. Physical model showing material diversity and lighting conditions

ements can create a unique mosaic of colors and textures interacting with the natural elements such as light and wind. This process of design was insinuated in the highly textured elevation drawing (Fig.35), but has to be perceived as a mere exploration of the infinite number of possible solutions. The nature of the building envelopes would form during the construction process, along with the resource availability and the constructor's imaginativeness. The physical model shown in the photos explores the visual qualities of this material diversity, as well as elements of texture and light (Fig.34).

The structural concept developed for this project offers many advantages: First it is affordable and can be built from readily available materials. It is also very important that it can be produced on site by non-specialized workforce. And finally, although it is durable, it can be easily dismantled and even transported for reconstruction on another site. 


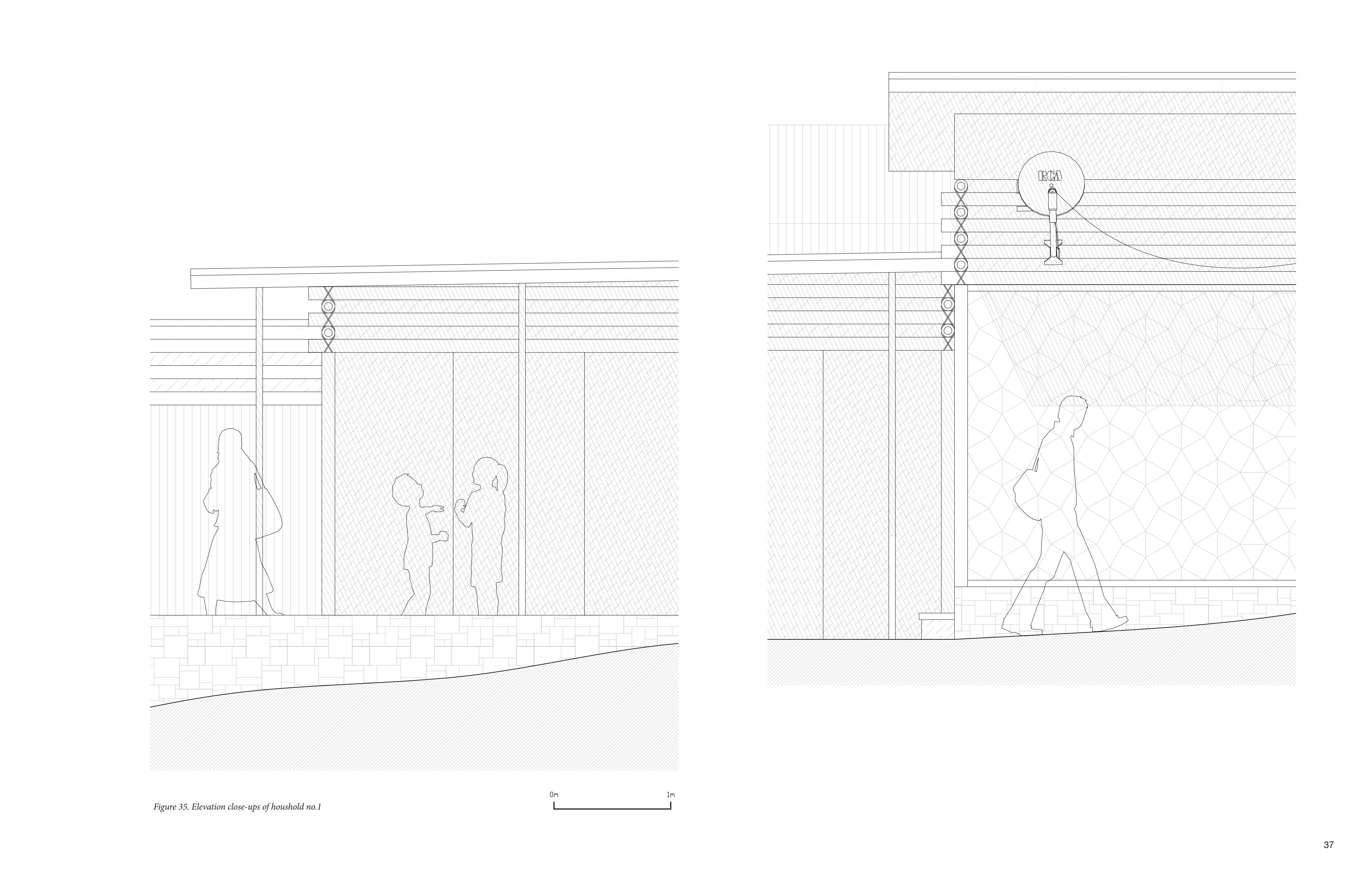




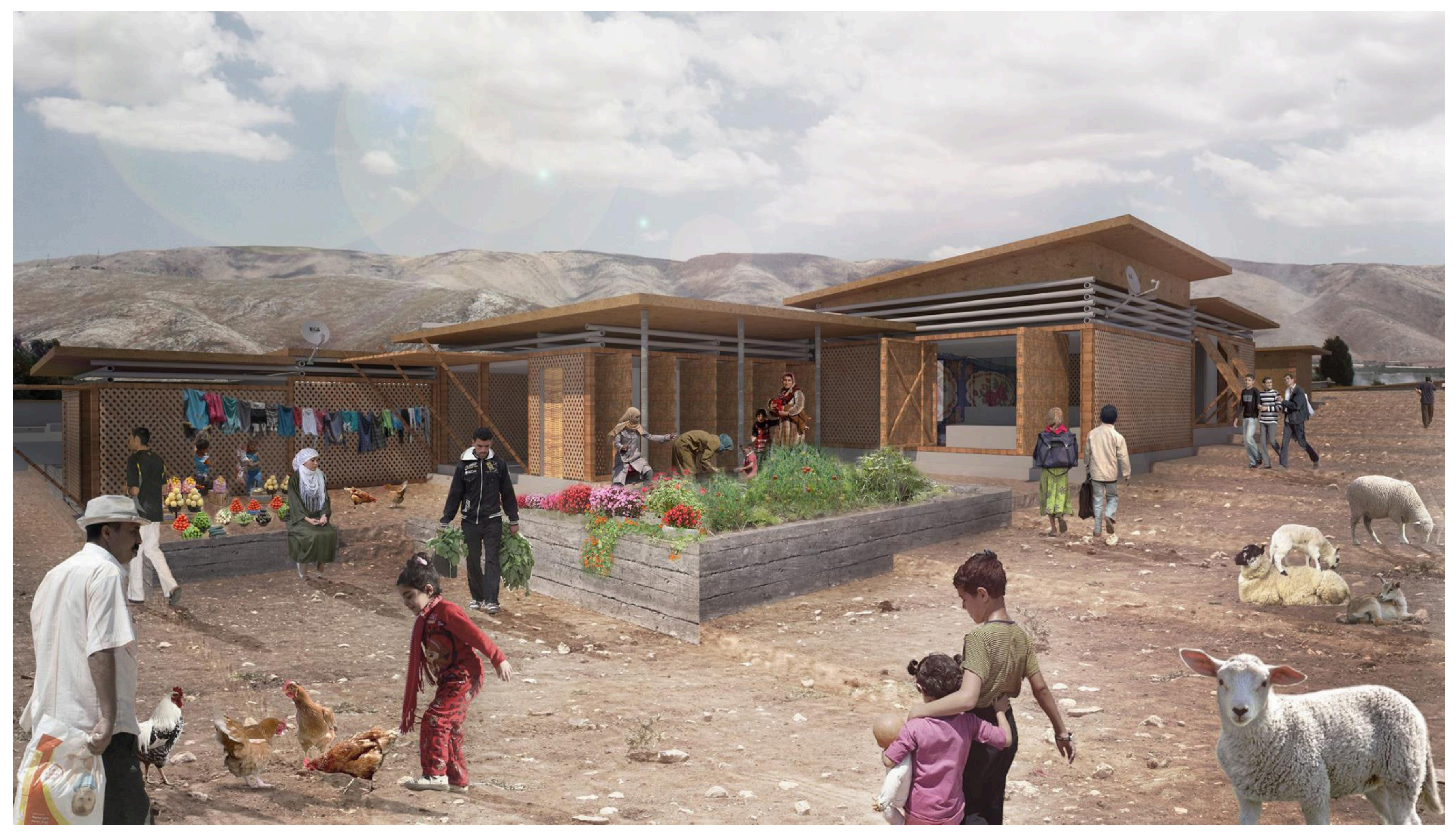



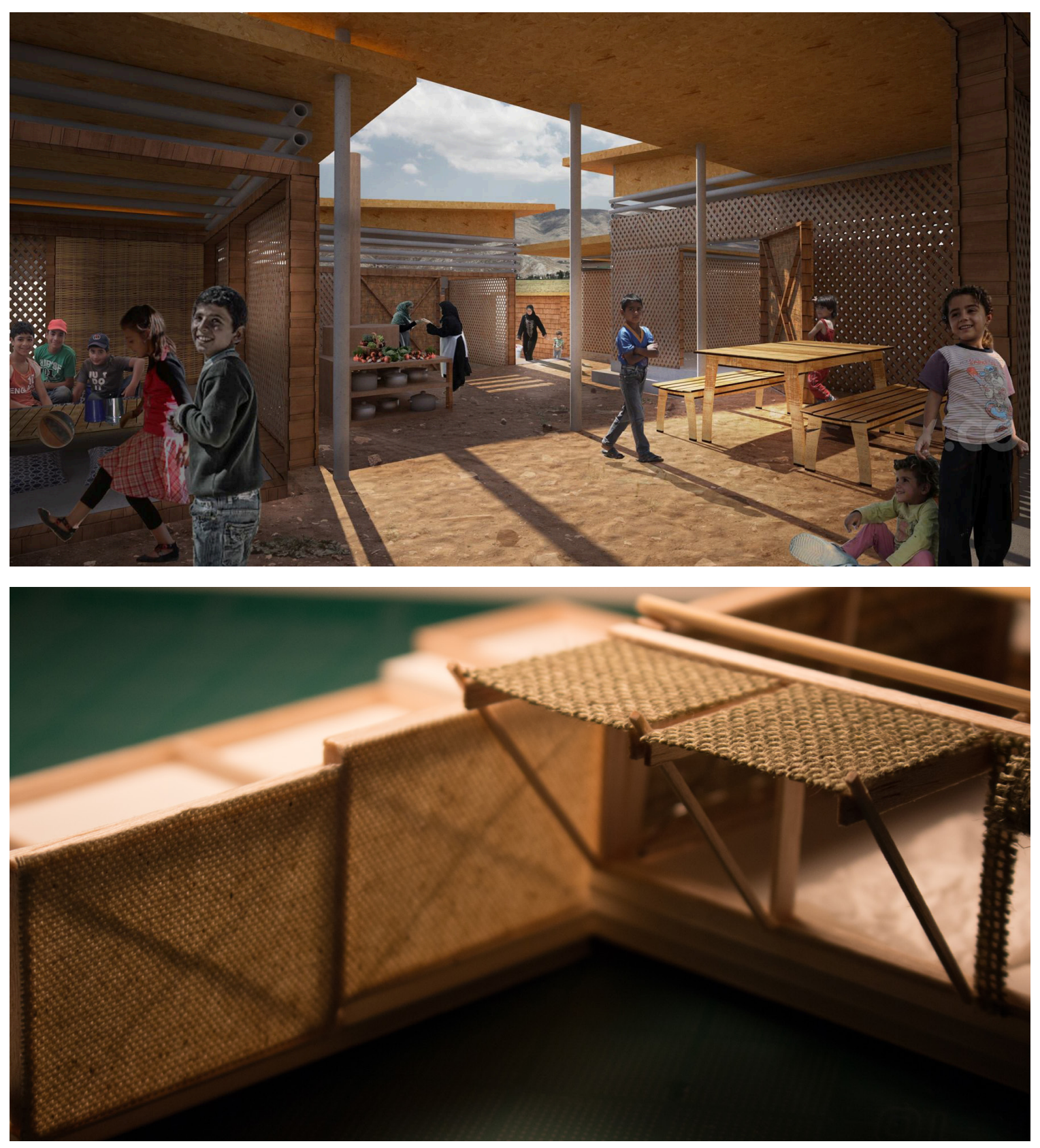

Figure 37. Rendered view of the shared courtyards

Figure 38. Physical model showing indoor-outdoor connection through tilting panels 

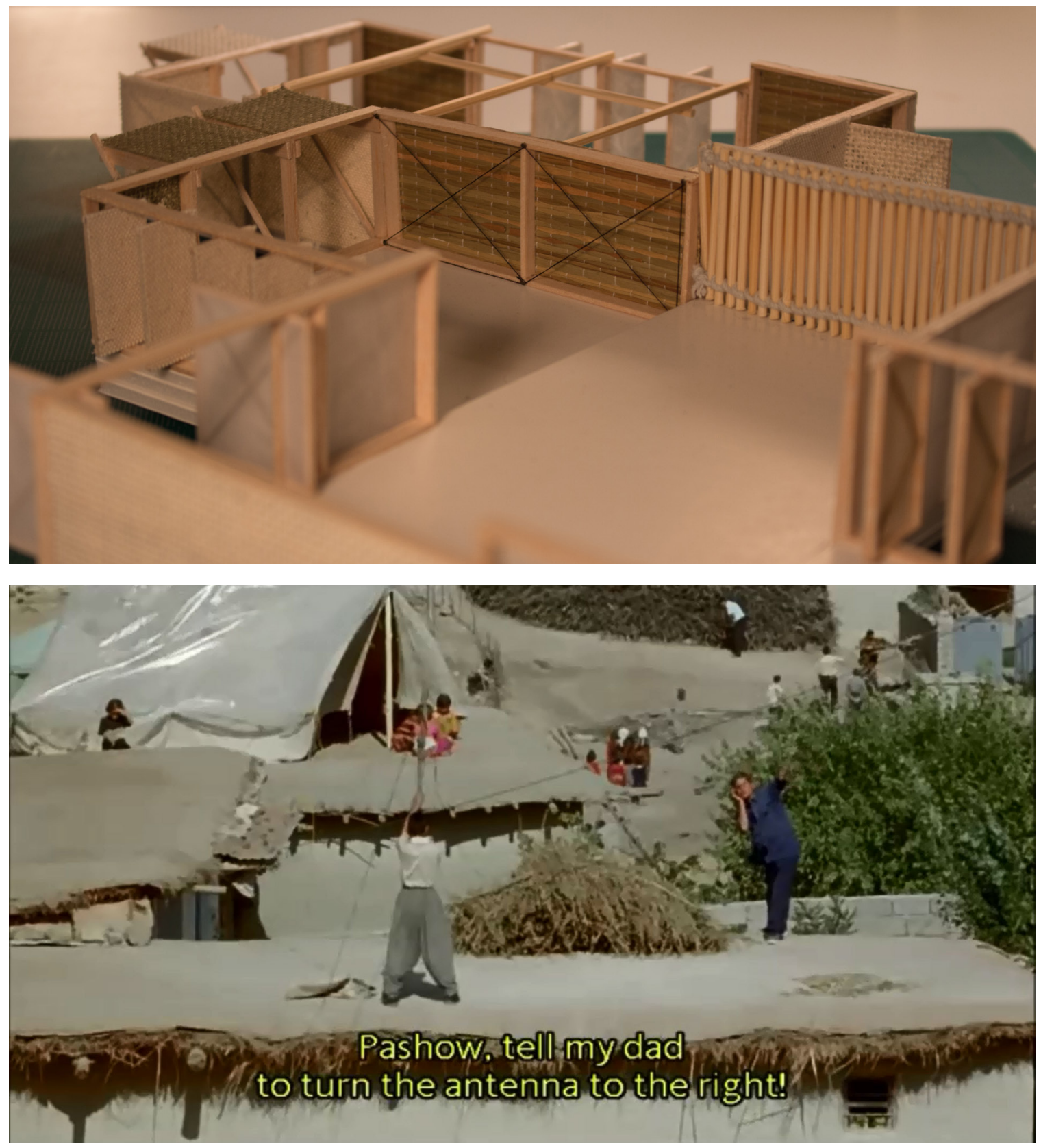

Figure 39. Physical model showing multi-level structure

Figure 40. Children installing antenna on roof. from the movie Turtles Can Fly. Bahman Ghobadi (dir.), IFC Films, 2004. 

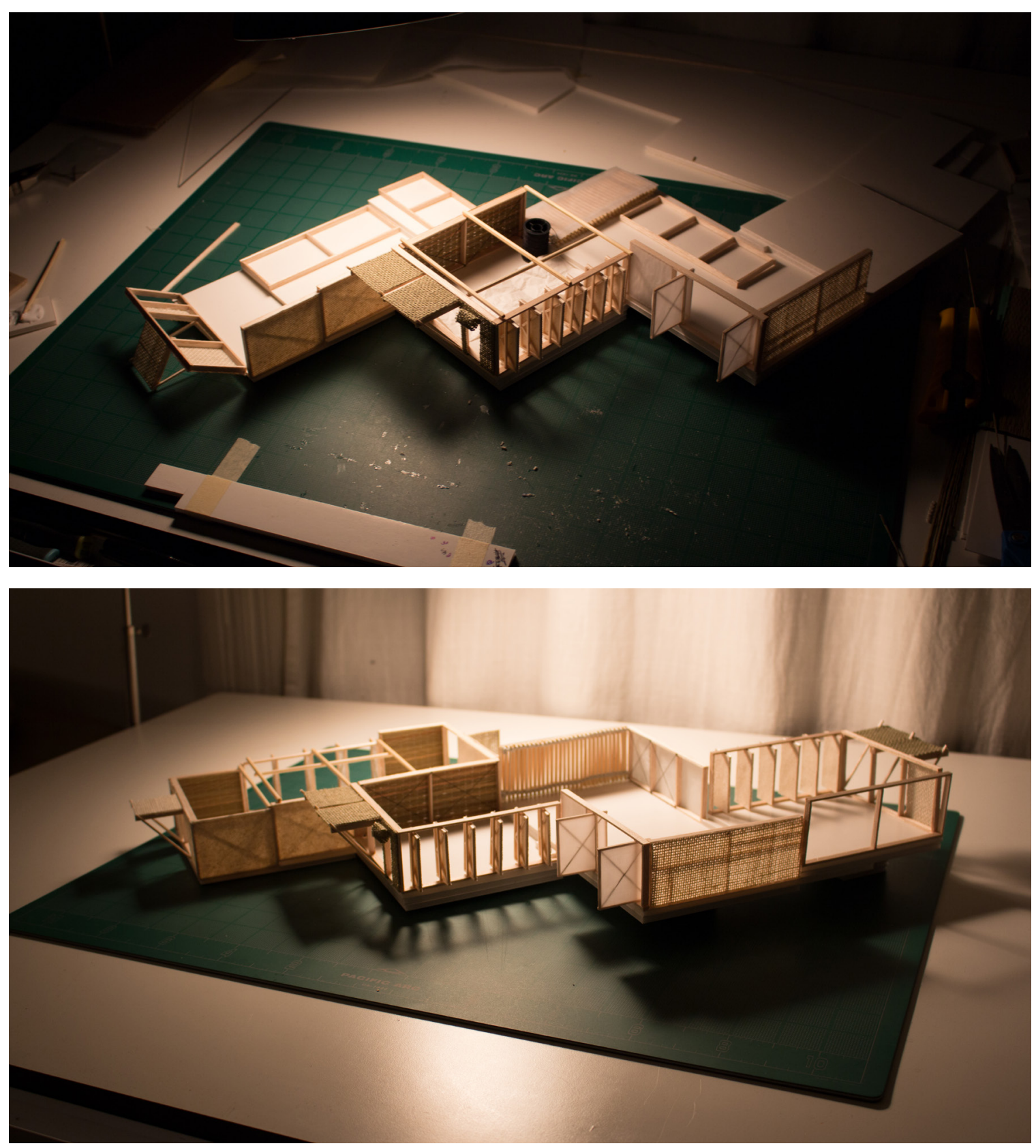

Figure 41. Physical model showing building process

Figure 42. Physical model of housing units complete with structure and exterior walls 

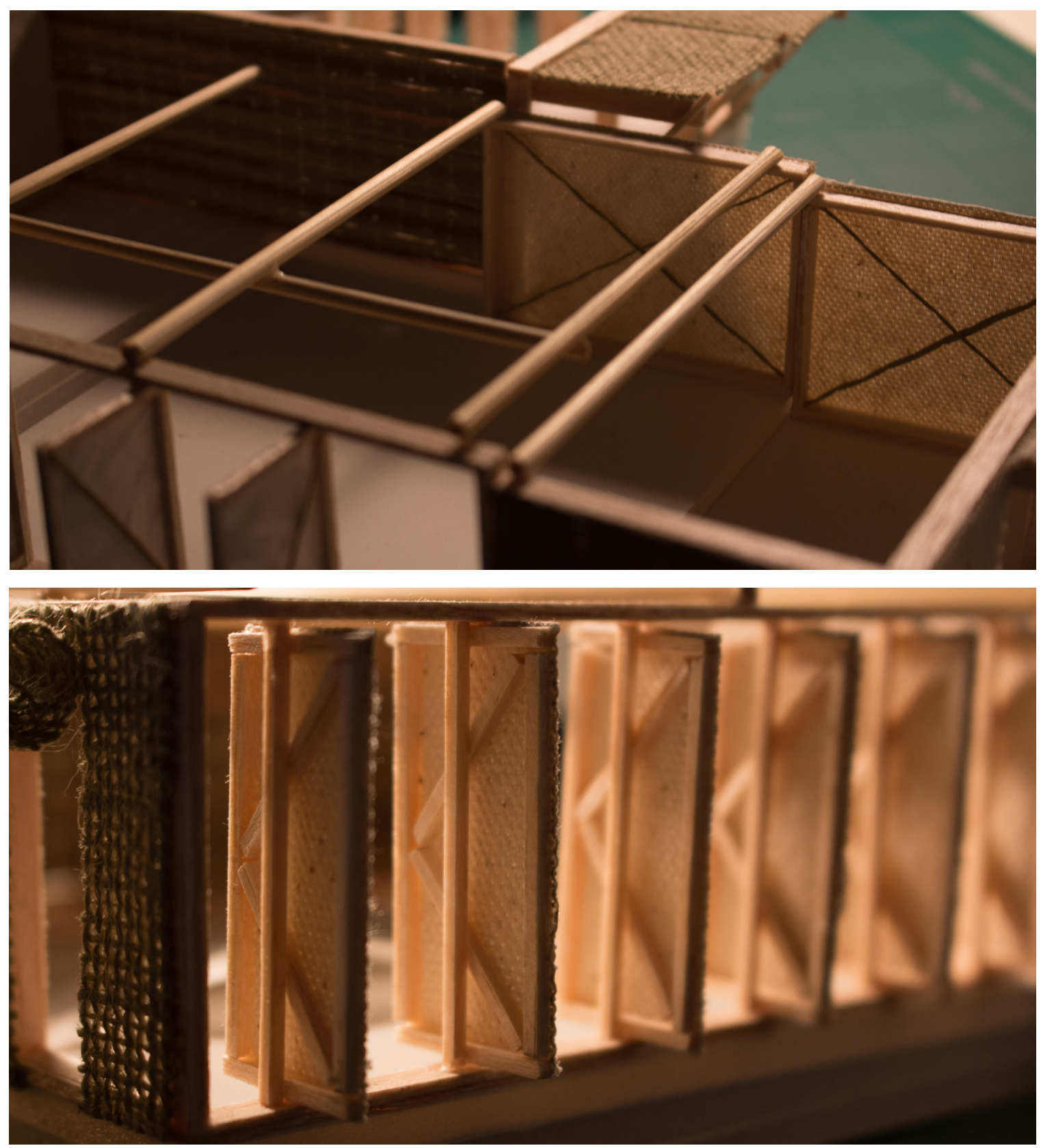

Figure 43. Physical model close-up of roof-supporting structure

Figure 44. Physical model close-up of rotating doors 

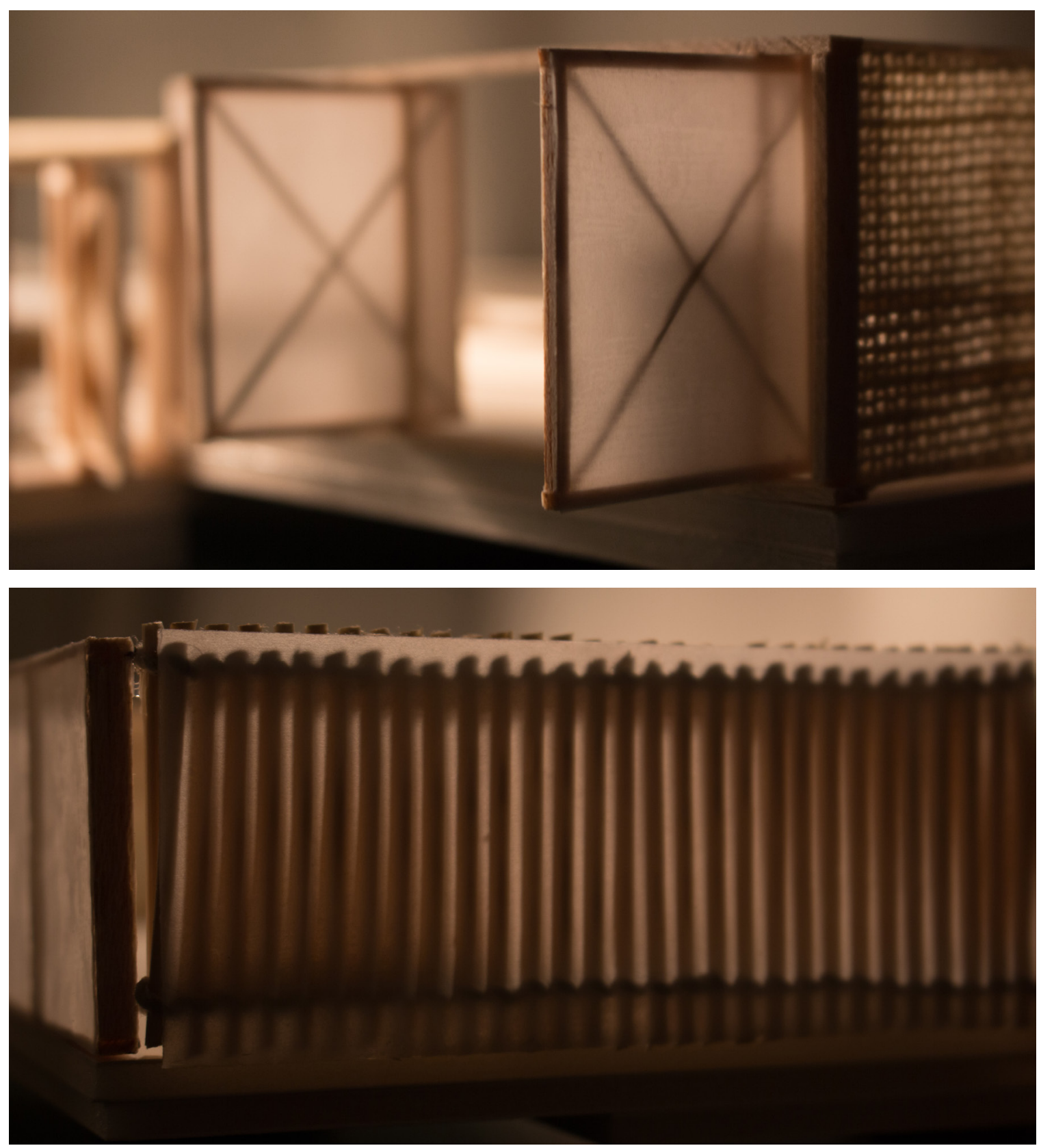

Figure 45. Physical model close-up of rotating doors

Figure 46. Physical model close-up of exterior wall 


\section{Postscript}

Despite the large number of non-profit organizations working on the improvement of the refugee condition, little attention has been given to elements such as architecture and design. In fact, the severity of the situation, combined with the total inactivity of the Lebanese government, has constrained the NGO's work to the most basic humanitarian activities. Although some international groups like Architecture for Humanity or Ikea have addressed the subject of disaster relief through architecture, there been no sign of intervention on the site.

The project presented in this thesis was developed with a full understanding of the complex social circumstances. Through this concept, the communities won't have to rely on the hierarchy in order to bring improvement to their living environments, as the dwellings can be built with very little means. Also, they would not need any particular building skills as the process is based on trial and error, allowing them to test new construction methods. The design can be further developped into a kit of parts, representing architectural elements through a varierty of constructive solutions that can be used to easily design, fabricate and assemble houses. The shifted module structure is an essential element of the project as it helps organizing the general layout of the settlement, which currently evolves in a sporadic manner. In order to implement the project, the concept would have to be explained to the community via an organization active on site. The construction process could be edited into a clear and concise guidebook, which can be distributed either in a printed version or virtually through the internet. A strategy has to be developed in order to maximize, at least theoretically, the accessibility of the final product to the target audience. With the assistance of an architect or a designer, the inhabitants will then develop on paper an architectural plan that is adapted to their living situation. The architect can also be consulted about technical issues like 
construction methods and material use. Once the dwelling plan is developed, the construction can be completed in timely steps, according to each family's means.

However, further research should be conducted in order to provide an adequate environment. The absence of a sewage infrastructure and a clean water source remain the major issues that the refugees are facing in the camps. A small scale water treatment and purification system could be easily integrated into the general plan in order to provide water autonomy to the inhabitants. Also, the exploration of potential alternative materials would be highly relevant in a context where waterproofing and thermal insulation are extremely costly.

Although the project was based on rigorous research and up-to-date data, the changing nature of the context can make it hard to predict the effectiveness of the response. Elements such as financial dependence, social insecurity or political discrimination can be serious obstacles for refugees trying to better their living condition. Furthermore, the proposed design might not be accepted as it currently is. The affected communities might find the design proposition to be too costly, too permanent or not dense enough. In order to improve it and ensure its suitability, the project needs to be tested, discussed and modified by the refugee communities, directly on the site. While the outcome of this project cannot be known, it has already fulfilled one of it purposes, which is to actively take part in the global humanitarian effort through academic research. Its true value lies in its adaptability and would best be measured as a vehicle for discussion and a model awaiting the discursive input of its final users. 


\section{Bibliography}

\section{Books}

AQUILINO, Marie J. Beyond Shelter: Architecture and Human Dignity. New York: Metropolis Books, 2011, 303 p.

Architecture for Humanity. Design Like You Give a Damn: Architectural Responses to Humanitarian Crises. New York: Metropolis books, 2006, 333 p.

Architecture for Humanity. Design Like You Give a Damn [2] : Building Change from the Ground Up. New York: Abrams books, 2012, 334 p.

AUGÉ, Marc. Non-Lieux : Introduction à une Anthropologie de la Surmodernité. Paris : Seuil, 1992, $149 \mathrm{p}$.

FRIEDMAN, Yona. L'architecture de Survie. Tournai: Casterman, 1978, 171 p.

HARELL-BOND, Barbara E. Imposing Aid: Emergency Assistance to Refugees. Oxford: Oxford University Press, 1986, $440 \mathrm{p}$.

LIZARRALDE, Gonzalo. Rebuilding After Disasters: From Emergency to Sustainability. London: Spon Press, 2010, 283 p.

LEPIK, Andres. Small Scale, Big Change: New Architectures of Social Engagement. New York: Museum of Modern Art, 2010, $139 \mathrm{p}$.

RAMROTH, William G. Planning for Disaster: How Natural and Manmade Disasters Shape the Built Environment. Chicago: Kaplan, 2007, 294 p.

SMITH, Cynthia E. Design for the Other 90\%. New York: Cooper-Hewitt, 2007, 144 p.

TSCHUMI, Bernard. The Manhattan Transcripts. New York: New ed., 1994, 63 p.

United Nations High Commissioner of Refugees. The State of the World's Refugees 2012: In Search of Solidarity. Oxford: Oxford University Press, 2012, 288 p.

\section{Publications}

International Organization for Migration (IOM). Transitional Shelter Guidelines. Geneva: Shelter Centre, 2012, 216 p.

The Sphere Project. "Chapter 4: Minimum Standards in Shelter, Settlement and Non-Food Items". Humanitarian Charter and Minimum Standards in Disaster Response. Oxford: Oxfam publishing, 2004, p. 205-229.

United Nations High Commissioner of Refugee. Convention and Protocol Relating to the Status of Refugees. Geneva: UN Public Information Section, 2010, 52 p.

United Nations High Commissioner of Refugees. UNHCR Handbook for Emergencies. Geneva: UNHCR, 2007, 582 p.

VERNER, Dorte, David R. LEE, Maximillian ASHWILL and Robert WILBY. Increasing Resilience to Climate Change in the Agricultural Sector of the Middle East. Washington DC: The World Bank, 2013, 140p. 


\section{Articles}

AGIER, Michel. "Between War and City - Towards an Urban Anthropology of Refugee Camps". Ethnography, vol. 3, no. 3, p. 317-341, 2002.

HYNDMAN, Jennifer. "Refugee Self-Management and the Question of Governance". Refuge, vol. 16, no. 2, 1997, p. 16-22, 1997.

NATHANAEL, Dorent. "Transitory Cities: Emergency architecture and the challenge of climate change". Development, vol. 54, no. 3, 2011, p. 345-351.

AUDEFROY, Joel F. "Haiti: post-earthquake lessons learned from traditional construction". Environment \& Urbanization, vol. 23, no. 2, 2011, p.447-462.

\section{Online Articles:}

HERTZ, Manuel. "Refugee Camps or Ideal Cities in Dust and Dirt". Retrieved September 17, 2014, from http://src.holcimfoundation.org/dnl/07d05702-63aa-4efc-8495-0e3a34b32acc/F07-WKTemp-herz02.pdf

SCHMIDT, Anna. "FMO Thematic Guide: Camps Versus Settlements". Retrieved September 17, 2014, from http://www.forcedmigration.org/research-resources/expert-guides/camps-versus-settlements /fmo021.pdf/view

United Nations High Commissioner for Refugees (UNHCR)(n.d.). Syria Regional Refugee Response. Retrieved December 5th, 2014, from http://data.unhcr.org/syrianrefugees/settlement. php? $i d=176 \&$ country $=107 \&$ region $=77$

\section{Other}

BOURDIEU, Pierre. "In Algeria - Testimonies of Uprooting". Edition Camera Austria, Graz Said, Edward, Orientalism, Penguin, London . Photography.

GHOBADI Bahman. Turtles Can Fly. IFC Films, 2004. Film.

Ground Zero Syria (Part 10) - Za'atari Refugee Camp. Vice, October 10, 2013. Documentary. 


\section{List of figures}

Fig 1: Satellite view of the Bekaa Region. Google Earth, March 2015.

Fig 2: Informal refugee settlement near Anjar, Lebanon. By Sammy Yehia, June 2014.

Fig 3: Cross section of Lebanese topography in East-West axis. By Sammy Yehia, 2015.

Fig 4: Still from the movie Turtles Can Fly. GHOBADI Bahman. Turtles Can Fly. IFC Films, 2004. Film.

Fig 5: Satellite view of the Bekaa Valley Region showing existing road and agricultural lands. Google Earth, March 2015.

Fig 6: Kurdish refugee children, from the movie Turtles Can Fly. GHOBADI Bahman. Turtles Can Fly. IFC Films, 2004. Film.

Fig 7: Latrines and livestock in a vacant basketball court, near a refugee camp in Anjar, Lebanon. By Sammy Yehia, June 2014.

Fig 8: Al Zaatari refugee camp in Jordan. UN Photo/Mark Garten. <http://www.syriarefugees.com/ timeline/zaatari-refugee-camp-opens-in-jordan/> (accessed March 2015).

Fig 9: Improvised housing near Anjar. By Sammy Yehia, June 2014.

Fig 10: Constructive solutions and material use in three different settlements around the Bekaa valley. By Sammy Yehia, 2015.

Fig 11: Dwelling cluster composed of modular housing and shared courtyards. By Sammy Yehia, 2015.

Fig 12: Roof plan of dwelling cluster. By Sammy Yehia, 2015.

Fig 13: Regional plan: Anjar and surrounding villages. By Sammy Yehia, 2015.

Fig 14: Courtyard houses in Aleppo, Syria. <http://design.epfl.ch/organicites/2010b/how/research/briefs/vernacular-lessons> (accessed September 2014).

Fig 15: Digital Sketches of traditional Syrian architecture (left) and refugee camp architecture (right). By Sammy Yehia, 2015.

Fig 16: Volumetric study of housing unit. By Sammy Yehia, 2015.

Fig 17: Terraced courtyards composition. By Sammy Yehia, 2015.

Fig 18: Interior courtyard of house in Aleppo, Syria. <http://www.telegraph.co.uk/travel/destinations/middleeast/syria/8310778/Aleppo-Syria-hotels-restaurants-and-packages.html> (accessed March 2015).

Fig 19: National Museum of Damascus courtyard. < http://www.flickr.com/photos/waltercallens/4685903624/> (accessed March 2015).

Fig 20: Interior courtyard at Madrasa Al Halawiya in Aleppo, Syria. < https://s-media-cache-ak0. pinimg.com/originals/90/76/e0/9076e09220a115fcae7e94fda6d0a33b.jpg (accessed March 2015). 
Fig 21: Diagram of housing cluster structure. By Sammy Yehia, 2015.

Fig 22: Refugee settlement layout. By Sammy Yehia, 2015.

Fig 23: Physical model of dwelling foundations. By Sammy Yehia, 2015.Fig 24: Household no.1 plan. By Sammy Yehia, 2015.

Fig 25: Household no.5 plan. By Sammy Yehia, 2015.

Fig 26: Household no.3 plan. By Sammy Yehia, 2015.

Fig 27: Household no.4 plan. By Sammy Yehia, 2015.

Fig 28: Household no.3 plan. By Sammy Yehia, 2015.

Fig 29: Household no.3 axonometric view: Living room and kitchen. By Sammy Yehia, 2015.

Fig 30: Physical model showing partial construction of a housing unit. By Sammy Yehia, 2015.

Fig 31: General plan of the refugee settlement cluster. By Sammy Yehia, 2015.

Fig 32: Elevation of the refugee settlement cluster. By Sammy Yehia, 2015.

Fig 33: Exploded axonometric view of dwelling. By Sammy Yehia, 2015.

Fig 34: Physical model showing material diversity and lighting conditions. By Sammy Yehia, 2015.

Fig 35: Elevation close-ups of houshold no.1. By Sammy Yehia, 2015.

Fig 36: Rendered view of dwellings and their private courtyards. By Sammy Yehia, 2015.

Fig 37: Rendered view of the shared courtyards. By Sammy Yehia, 2015.

Fig 38: Physical model showing indoor-outdoor connection through tilting panels. By Sammy Yehia, 2015.

Fig 39: Physical model showing indoor-outdoor connection through tilting panels. By Sammy Yehia, 2015.

Fig 40: Children installing antenna on roof. from the movie Turtles Can Fly. GHOBADI Bahman. Turtles Can Fly. IFC Films, 2004. Film.

Fig 41: Physical model showing building process. By Sammy Yehia, 2015.

Fig 42: Physical model of housing units complete with structure and exterior walls. By Sammy Yehia, 2015.

Fig 43: Physical model close-up of roof-supporting structure. By Sammy Yehia, 2015.

Fig 44: Physical model close-up of rotating doors. By Sammy Yehia, 2015.

Fig 45: Physical model close-up of rotating doors. By Sammy Yehia, 2015.

Fig 46: Physical model close-up of exterior wall. By Sammy Yehia, 2015. 


\section{Appendix A}

\section{Al Zaatari refugee camp, Jordan}

Al-Zaatari is a refugee camp located $10 \mathrm{~km}$ east of the city Mafraq in Jordan, and about $20 \mathrm{~km}$ south of the Syrian frontier. It was first opened on the 28th of July 2012 to host Syrians fleeing the violence of the civil war. In July 2013, the camp's population was estimated at 140000 refugees making it Jordan's fourth largest city. The study of the existing infrastructure will be done through a visual analysis of satellite images and data maps published by $\mathrm{REACH}$, a data-collection organization.

The first map (Fig.1) consists of four satellite images showing the expansion of the Al-Zaatari camp between the 15th of November 2012 and the 26th of February 2013. The dashed red line represents the camp's extent while the orange dots represent the shelter structures and the blue dots represent the administrative and other structures. The evolution of the numbers shows an explosive augmentation of the camp's population during the three and a half months period. While the area of the camp had almost tripled, the number of shelters was five times higher. On the other hand, the ratio of administrative buildings to the number of shelters was cut in half. These numbers show the importance of careful planning so to avoid the overwhelming of the infrastructure and the decrease of the living standards.

The second map (Fig.2) represents the existing infrastructure inside the camp. Composed of twelve districts, the camp has only one access point in the north-west corner. It is equipped with health facilities, distribution centers, schools, mosques, police stations, recreation areas and child friendly spaces. It is also equipped with two pumping stations, one in the north and the other in south, supplying water to the multiple tanks and water points. There are two market-like structures along the main streets where the refugees can purchase food supplies, basic household equipment and clothes. Throughout the camp, the shelter structures are clustered into groups of different sizes, each of them sharing a kitchen area and a washing facility. While the older parts 
of the camp, in the north-west region, seem to be condensed and crowded, the newest sections are more spaced and structured, following an orthogonal grid. A number of institutional buildings (like school and health clinics) are under construction in order to fulfil the growing needs of the community.

The third and fourth (Fig.3,4) maps relate the housing conditions throughout the campsite. The readings on the first one show that a majority of shelters are over populated, hosting more than the standard of five individuals. Only a minority of about $30 \%$ seem to be living above the shelter allocation standard. The latter illustrates the types of structures inhabited by the refugee, with about half of the population living in lightweight tents and the other half in caravans.

Almost a year and a half after the creation of the camp, there are only two types of accommodation available to the inhabitants, both of which have advantages and disadvantages. The emergency tents cost about $100 \$$ each and can shelter up to 5 people. Their lifespan of only 6 months makes them a non-sustainable choice. They are also vulnerable to natural elements. On several occasions, the camp was flooded due to heavy rainfall and the tents were damaged forcing families to seek refuge with neighbours and relatives who have pre-fabricated trailers. The second alternative is the caravan, prefabricated in the gulf countries and shipped to Jordan. They are resistant to cold winters but tend to overheat during the summer. They can shelter up to 6 people and have been reported to cost between $300 \$$ and $600 \$$ inside the camp. Their actual cost of production and shipping is unknown. With a lifespan of up to 3 years, they are more sustainable than the tents. In some cases, the residents have resorted to the construction of improvised structures using salvaged materials (like wood, corrugated metal and plastic canvas) sold inside the camp at very high prices.

The obvious lack of accommodation in one of the best managed camps of the region highlights the necessity of a creative and practical response that would bring long term stability to these settlements. 


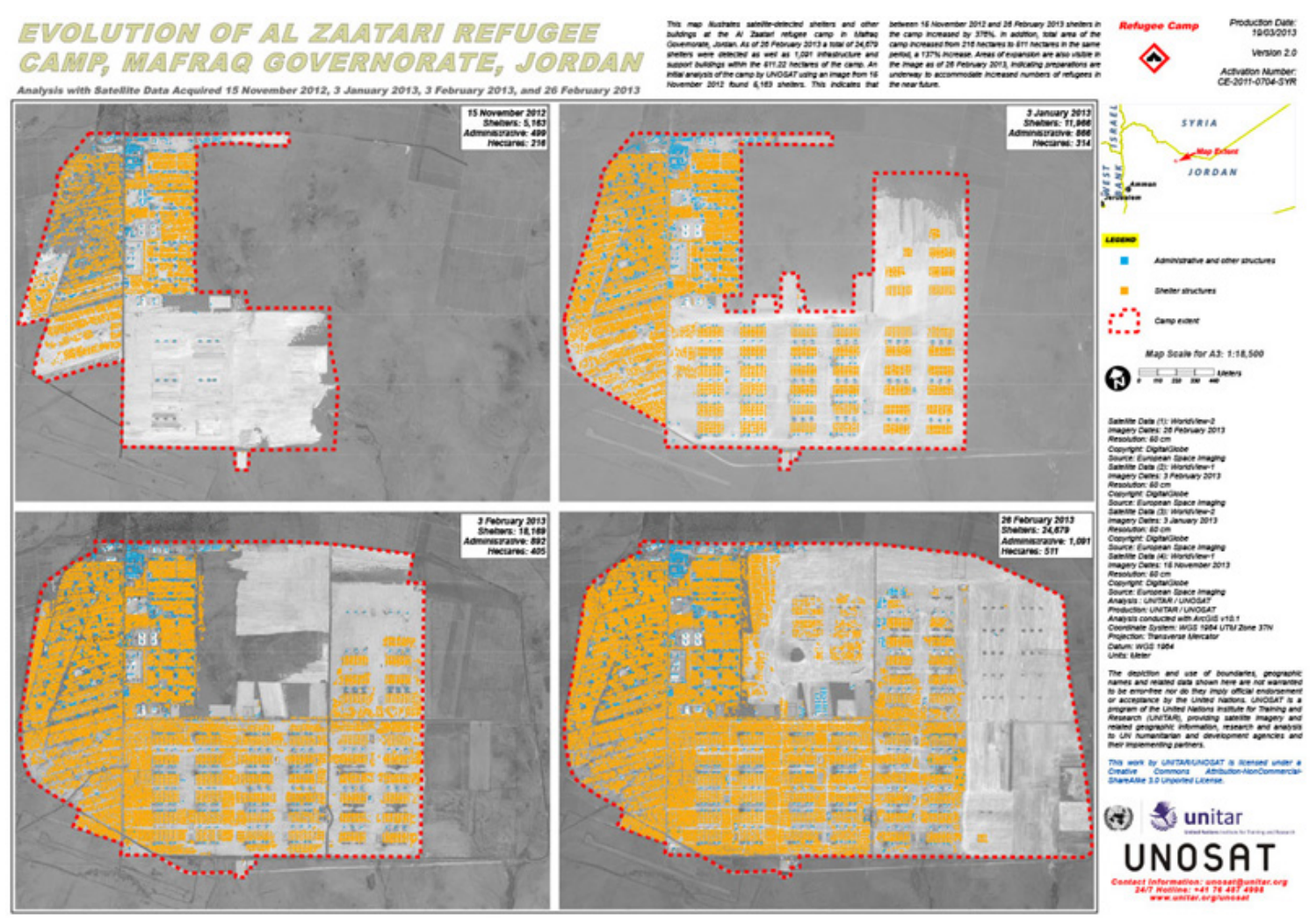

Fig 1: Evolution of Al Zaatari Camp 2012-2013

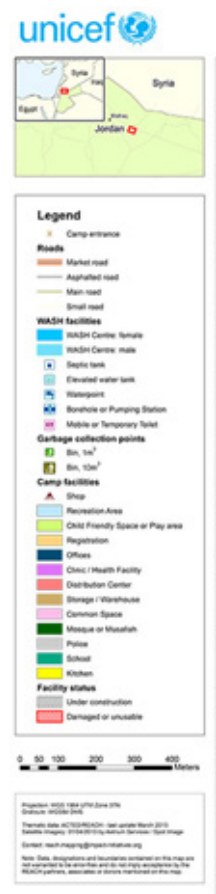

Al Zaatari Refugee Camp - General Infrastructure

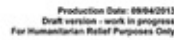

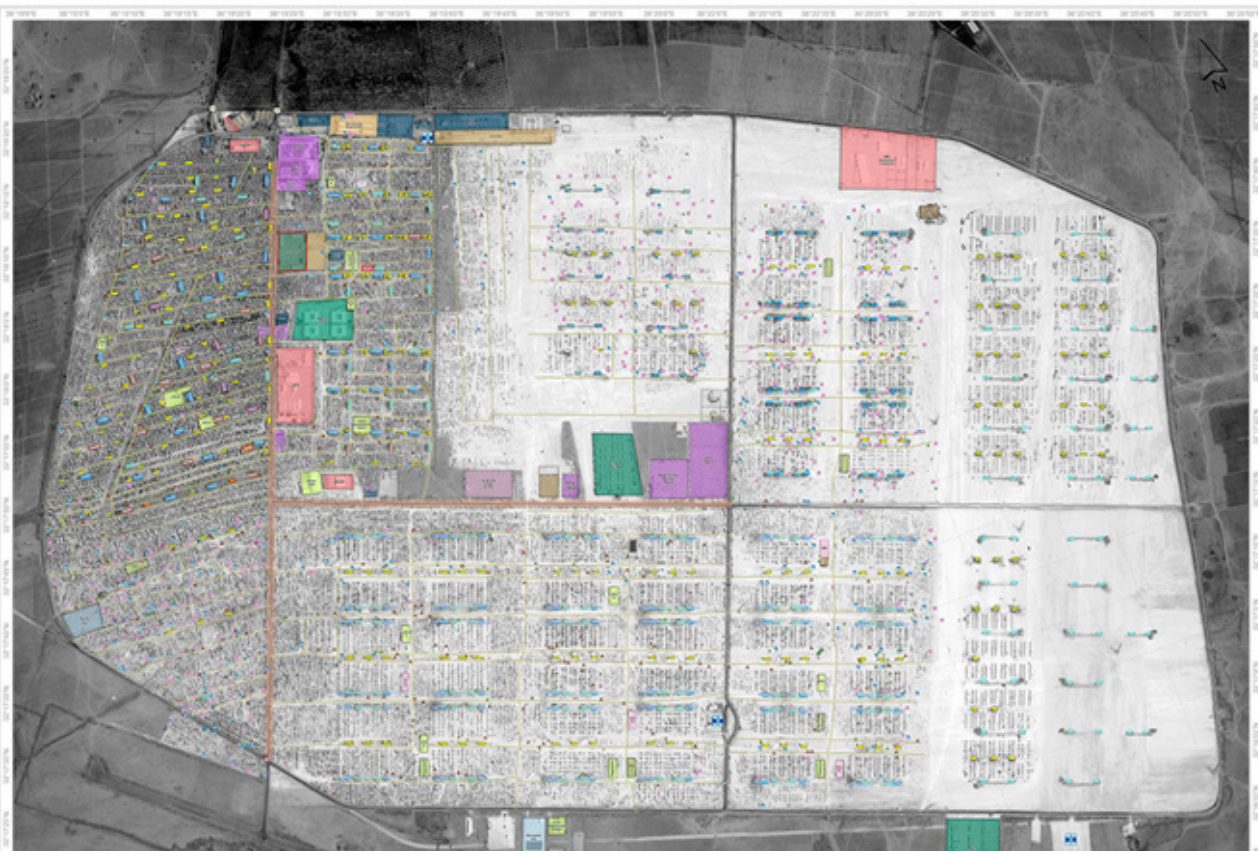

Fig 2: General infrastructure of Al Zaatari Camp 
(8) ACTED AI Zaatari Refugee Camp - Shelter allocation per family meeting the standards: 30-MAY-2013 , int

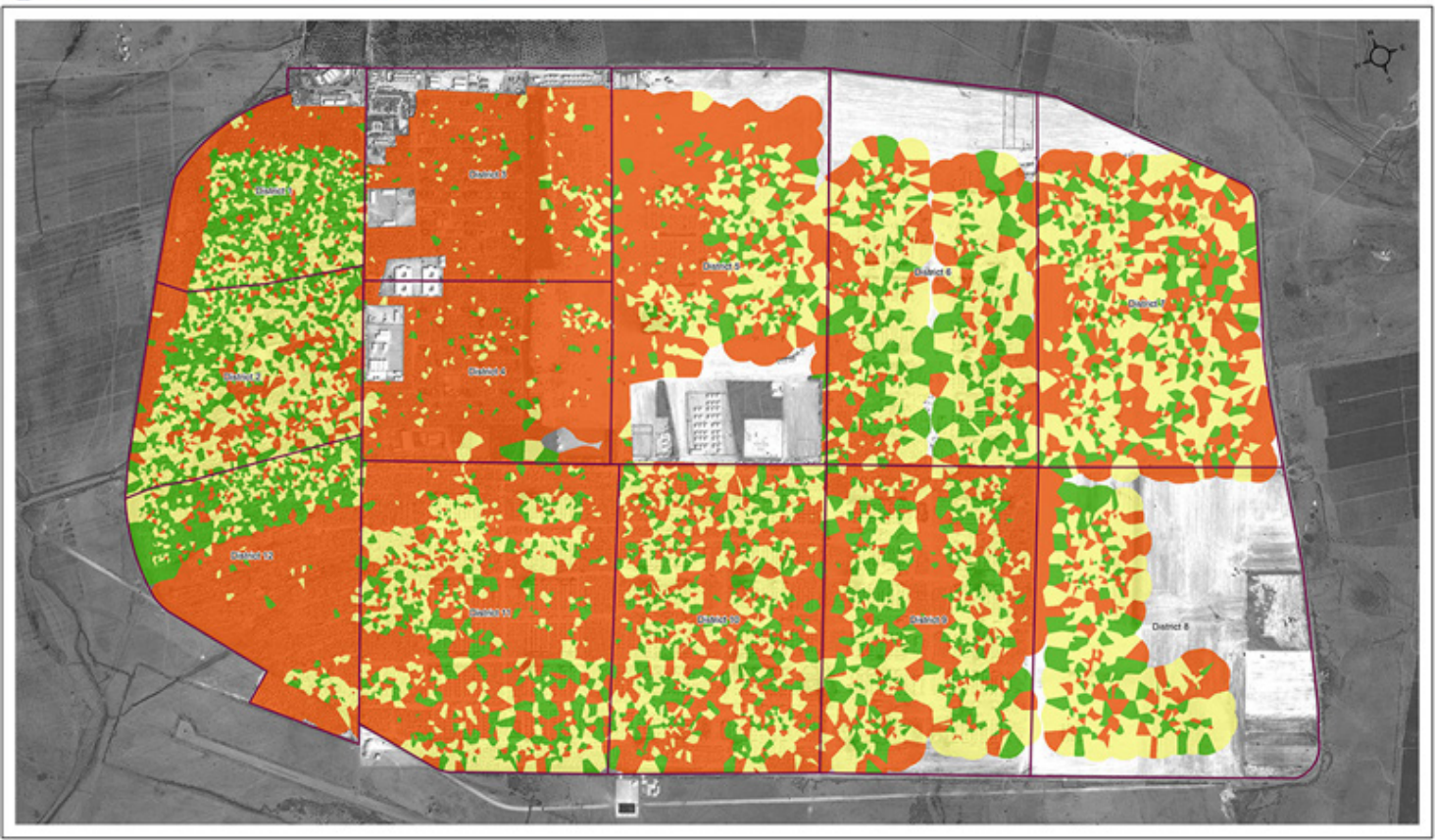

Fig 3: Shelter allocation per family meeting the standards, Al Zaatari Camp

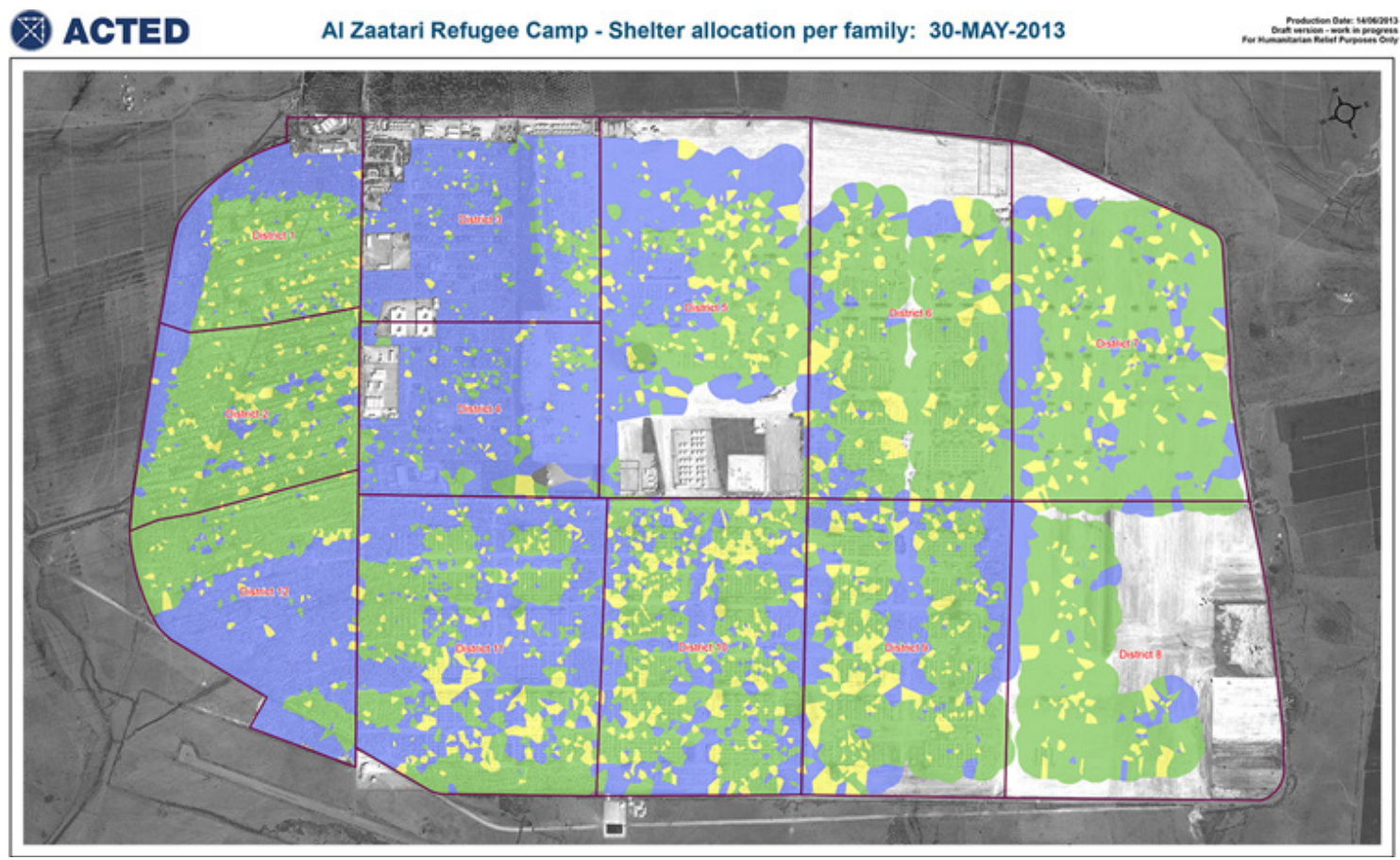

Fig 4: Shelter allocation per family in Al Zaatari Camp 